\title{
Distinct Roles of PDE4 and PDE10A in the Regulation of cAMP/PKA Signaling in the Striatum
}

\author{
Akinori Nishi, ${ }^{1,2,4}$ Mahomi Kuroiwa, ${ }^{1}$ Diane B. Miller, ${ }^{3}$ James P. O'Callaghan, ${ }^{3}$ Helen S. Bateup, ${ }^{4}$ Takahide Shuto, ${ }^{1}$ \\ Naoki Sotogaku, ${ }^{1}$ Takaichi Fukuda, ${ }^{6}$ Nathaniel Heintz, ${ }^{5}$ Paul Greengard, ${ }^{4}$ and Gretchen L. Snyder ${ }^{7}$ \\ ${ }^{1}$ Department of Pharmacology, Kurume University School of Medicine and ${ }^{2} J a p a n$ Science of Technology Agency, Core Research for Evolutional Science \\ and Technology, Kurume, Fukuoka 830-0011, Japan, ${ }^{3}$ Centers for Disease Control and Prevention, National Institute for Occupational Safety and Health, \\ Morgantown, West Virginia 26505, ${ }^{4}$ Laboratory of Molecular and Cellular Neuroscience and ${ }^{5}$ Laboratory of Molecular Biology, The Rockefeller University, \\ New York, New York 10021, 'Department of Anatomy and Neurobiology, Graduate School of Medical Sciences, Kyushu University, Fukuoka 812-8582, \\ Japan, and ${ }^{7}$ Intra-Cellular Therapies, Inc., New York, New York 10032
}

Phosphodiesterase (PDE) is a critical regulator of cAMP/protein kinase A (PKA) signaling in cells. Multiple PDEs with different substrate specificities and subcellular localization are expressed in neurons. Dopamine plays a central role in the regulation of motor and cognitive functions. The effect of dopamine is largely mediated through the cAMP/PKA signaling cascade, and therefore controlled by PDE activity. We used in vitro and in vivo biochemical techniques to dissect the roles of PDE4 and PDE10A in dopaminergic neurotransmission in mouse striatum by monitoring the ability of selective PDE inhibitors to regulate phosphorylation of presynaptic [e.g., tyrosine hydroxylase (TH)] and postsynaptic [e.g., dopamine- and cAMP-regulated phosphoprotein of $\mathrm{M}_{r} 32 \mathrm{kDa}$ (DARPP-32)] PKA substrates. The PDE4 inhibitor, rolipram, induced a large increase in TH Ser40 phosphorylation at dopaminergic terminals that was associated with a commensurate increase in dopamine synthesis and turnover in striatum in vivo. Rolipram induced a small increase in DARPP-32 Thr34 phosphorylation preferentially in striatopallidal neurons by activating adenosine $A_{2 \mathrm{~A}}$ receptor signaling in striatum. In contrast, the PDE10A inhibitor, papaverine, had no effect on TH phosphorylation or dopamine turnover, but instead robustly increased DARPP-32 Thr34 and GluR1 Ser845 phosphorylation in striatal neurons. Inhibition of PDE10A by papaverine activated cAMP/PKA signaling in both striatonigral and striatopallidal neurons, resulting in potentiation of dopamine $\mathrm{D}_{1}$ receptor signaling and inhibition of dopamine $\mathrm{D}_{2}$ receptor signaling. These biochemical results are supported by immunohistochemical data demonstrating differential localization of PDE10A and PDE4 in striatum. These data underscore the importance of individual brain-enriched cyclic-nucleotide PDE isoforms as therapeutic targets for neuropsychiatric and neurodegenerative disorders affecting dopamine neurotransmission.

Key words: phosphodiesterase; DARPP-32; tyrosine hydroxylase; immunohistochemistry; rolipram; papaverine

\section{Introduction}

Dopamine plays a central role in the regulation of motor and cognitive functions. The cAMP/protein kinase A (PKA) signaling cascade is essential for dopamine neurotransmission. Dopamine, acting on $\mathrm{D}_{1}$ receptors, stimulates cAMP/PKA signaling via $\mathrm{G}_{\mathrm{s} / \mathrm{olf}}{ }^{-}$ mediated activation of adenylyl cyclase (Hervé et al., 2001), whereas dopamine, acting on $\mathrm{D}_{2}$ receptors, inhibits cAMP/PKA signaling via $\mathrm{G}_{\mathrm{i}}$-mediated inactivation of adenylyl cyclase (Stoof and Kebabian, 1981). In mammalian striatum, the synthesis of dopamine by tyrosine hydroxylase (TH) (Harada et al., 1996;

Received May 30, 2008; revised July 27, 2008; accepted Aug. 29, 2008.

This work was supported by a Grant-in-Aid for Scientific Research from the Japan Society for the Promotion of Science (18300128 to A.N.), grants from the United States Public Health Service (MH40899 and DA10044 to P.G.; MH067488 to G.L.S.), the Picower Foundation (P.G.), the Michael Stern Parkinson's Research Foundation (P.G.), and the Department of Defense (DAMD17-02-1-00705 to P.G. and DAMD17-03-1-0396 and W81XWH-04-2-0009 to G.L.S.). We thank Yukako Terasaki, Keiko Fujisaki, Michiko Koga, Chris Felton, Fang Xiao Ma, Minal Rana, and Tiffany Tsui for excellent technical assistance.

Correspondence should be addressed to Dr. Akinori Nishi, Department of Pharmacology, Kurume University School of Medicine, 67 Asahi-machi, Kurume, Fukuoka 830-0011, Japan. E-mail: nishia@med.kurume-u.ac.jp. DOI:10.1523/JNEUROSCI.2518-08.2008

Copyright $\odot 2008$ Society for Neuroscience $\quad 0270-6474 / 08 / 2810460-12 \$ 15.00 / 0$
Dunkley et al., 2004) and the release of dopamine from nigrostriatal dopaminergic terminals (Zhu et al., 2004; Seino and Shibasaki, 2005) are regulated by the cAMP/PKA signaling cascade. In postsynaptic striatal neurons, DARPP-32, a dopamine- and cAMP-regulated phosphoprotein of $\mathrm{M}_{r} 32 \mathrm{kDa}$, is a major target for the cAMP/PKA signaling cascade (Greengard et al., 1999; Svenningsson et al., 2004). DARPP-32 is expressed in both the $\mathrm{D}_{1}$ receptor-enriched striatonigral and $\mathrm{D}_{2}$ receptor-enriched striatopallidal neurons (Bateup et al., 2008). Phosphorylation at Thr34 by PKA converts DARPP-32 into a potent inhibitor of the widespectrum protein phosphatase-1 (PP-1). The inhibition of PP-1 thereby controls the phosphorylation state and activity of many downstream physiological effectors, including various neurotransmitter receptors and voltage-gated ion channels. Mice lacking DARPP-32 are deficient in their molecular, electrophysiological, and behavioral responses to dopamine, drugs of abuse, and antipsychotic medication, indicating an essential role for DARPP-32 in dopaminergic signaling (Fienberg et al., 1998).

Dopaminergic signaling is controlled by phosphodiesterases (PDEs), which degrade cAMP and downregulate cAMP/PKA signaling. PDEs are encoded by 21 genes and subdivided into 11 
families according to structural and functional properties (Bender and Beavo, 2006). The brain expression and subcellular localization of PDE families are tightly regulated. Multiple PDEs are expressed in neurons, each with distinct roles in cAMP and cyclic GMP (cGMP) signaling. Several PDE families are expressed in striatum (Menniti et al., 2006). For example, PDE1B is abundantly expressed in striatum (Polli and Kincaid, 1994). Mice lacking PDE1B exhibit increased DARPP-32 phosphorylation at Thr34, indicating that PDE1B normally downregulates cAMP/ PKA signaling in striatal neurons (Reed et al., 2002). The role of other PDEs, such as PDE4 and PDE10A, in regulating the DARPP-32 signaling pathway is unknown. PDE10A is highly enriched in striatum (Fujishige et al., 1999; Coskran et al., 2006; Xie et al., 2006). Inhibition of PDE10A by papaverine increases phosphorylation of cAMP-dependent substrates, including the cAMP-response element-binding protein (CREB) and extracellular receptor kinase (ERK), by activating cAMP/PKA signaling (Siuciak et al., 2006b). PDE4B, another striatal-enriched PDE, likely plays a regulatory role in dopaminergic neurotransmission because inhibition of PDE4 by rolipram stimulates dopamine synthesis (Kehr et al., 1985; Schoffelmeer et al., 1985; Yamashita et al., 1997a). However, the precise role of PDE4 in dopaminergic neurotransmission is currently unknown.

Here, we identify distinct roles for PDE4 and PDE10A in cAMP/PKA signaling in striatonigral and striatopallidal neurons and at dopaminergic terminals. PDE10A predominantly regulates DARPP-32 phosphorylation in the same direction as a dopamine $\mathrm{D}_{2}$ antagonist in striatopallidal neurons, whereas PDE4 predominantly regulates $\mathrm{TH}$ phosphorylation at dopaminergic terminals. Thus, PDE4 and PDE10A have distinct roles in striatal dopaminergic neurotransmission conferred by their discrete cellular localization.

\section{Materials and Methods}

Preparation and incubation of neostriatal slices. Male C57BL/6 mice at 6-8 weeks old were purchased from Japan SLC. All mice used in this study were handled in accordance with the Declaration of Helsinki and with the Guide for the Care and Use of Laboratory Animals as adopted and promulgated by the National Institutes of Health, and the specific protocols were approved by the Institutional Animal Care and Use Committee of Kurume University School of Medicine. Male C57BL/6 mice were killed by decapitation. The brains were rapidly removed and placed in ice-cold, oxygenated Krebs- $\mathrm{HCO}_{3}^{-}$buffer [(in mM) $124 \mathrm{NaCl}, 4 \mathrm{KCl}, 26$ $\mathrm{NaHCO}_{3}, 1.5 \mathrm{CaCl}_{2}, 1.25 \mathrm{KH}_{2} \mathrm{PO}_{4}, 1.5 \mathrm{MgSO}_{4}$, and 10 D-glucose, $\mathrm{pH}$ 7.4]. Coronal slices $(350 \mu \mathrm{m})$ were prepared using a vibrating blade microtome, VT1000S (Leica Microsystems), as described previously (Nishi et al., 2005). Striata were dissected from the slices in ice-cold Krebs- $\mathrm{HCO}_{3}^{-}$buffer. Each slice was placed in a polypropylene incubation tube with $2 \mathrm{ml}$ of fresh $\mathrm{Krebs}-\mathrm{HCO}_{3}^{-}$buffer containing adenosine deaminase $(10 \mu \mathrm{g} / \mathrm{ml})$. The slices were preincubated at $30^{\circ} \mathrm{C}$ under constant oxygenation with $95 \% \mathrm{O}_{2} / 5 \% \mathrm{CO}_{2}$ for $60 \mathrm{~min}$. The buffer was replaced with fresh Krebs- $\mathrm{HCO}_{3}^{-}$buffer after 30 min of preincubation. Adenosine deaminase was included during the first $30 \mathrm{~min}$ of preincubation. Slices were treated with drugs as specified in each experiment. Drugs were obtained from the following sources: papaverine, 6-chloro-2,3,4,5-tetrahydro-1-phenyl-1H-3-benzazepine hydrobromide (SKF81297), $R-(+)-7$-chloro-8-hydroxy-3-methyl-1phenyl-2,3,4,5-tetrahydro-1H-3-benzazepine (SCH23390), and 2-p(2-carboxyethyl)phenethylamino-5- $\mathrm{N}$-ethylcarboxamidoadenosine (CGS21680) from Sigma-Aldrich; rolipram, 4-(2-[7-amino-2-(2-furyl)] trizolo[2,3-a] [1,3,5] triazin-5-ylamino]ethyl)phenol (ZM241385), and 1H$[1,2,4]$ oxadiazolo[4,3-a]quinoxalin-1-one (ODQ) from Tocris Bioscience. After drug treatment, slices were transferred to Eppendorf tubes, frozen on dry ice, and stored at $-80^{\circ} \mathrm{C}$ until assayed.

Frozen tissue samples were sonicated in boiling $1 \%$ SDS and boiled for an additional $10 \mathrm{~min}$. Small aliquots of the homogenate were retained for protein determination by the BCA protein assay method (Pierce). Equal amounts of protein $(40 \mu \mathrm{g})$ were loaded onto $4-12 \%$ polyacrylamide Bis-Tris gels (\#345-0124; Bio-Rad), separated by electrophoresis, and transferred to nitrocellulose membranes $(0.2 \mu \mathrm{m})$ (Schleicher and Schuell).

Immunoprecipitations of Flag- and Myc-tagged DARPP-32 in neostriatal slices from $\mathrm{D}_{1}$-DARPP-32-Flag/ $\mathrm{D}_{2}$-DARPP-32-Myc mice. $D_{1^{-}}$ DARPP-32-Flag/D ${ }_{2}-D A R P P-32-M y c$ transgenic mice express Flag- and Myc-tagged DARPP-32 under the control of dopamine $\mathrm{D}_{1}$ and $\mathrm{D}_{2}$ receptor promoters, respectively (Bateup et al., 2008). In the striatum, Flagtagged DARPP-32 was shown to be expressed selectively in $D_{1}$ receptorenriched striatonigral neurons, and Myc-tagged DARPP-32 selectively in $\mathrm{D}_{2}$ receptor-enriched striatopallidal neurons. Using antibodies against Flag and Myc tags, we can selectively immunoprecipitate DARPP-32 from $\mathrm{D}_{1}$ receptor- and $\mathrm{D}_{2}$ receptor-expressing neurons and analyze the phosphorylation state of DARPP-32 in a neuronal type-specific manner. In each experiment, six striatal slices were prepared from one mouse, and were divided into three treatment conditions. In each treatment condition, six slices, collected from three mice (two slices from each mouse), were used for the analysis of DARPP-32 phosphorylation. Six striatal slices were sonicated in $720 \mu \mathrm{l}$ of immunoprecipitation (IP) lysis buffer [50 mm Tris-HCl, pH 7.5, 150 mм NaCl, 1 mm EDTA, $1 \%$ Triton X-100, $1 \%$ SDS, $100 \mathrm{~nm}$ okadaic acid, phosphatase inhibitor mixture (\#P5726; Sigma-Aldrich), and protease inhibitor mixture (\#11873580001; Roche)]. After determination of protein concentration, $15 \mu \mathrm{g}$ of protein was saved for the analysis of DARPP-32 phosphorylation in total striatal homogenate, and the residual homogenates were used for IPs. In each IP from striatal homogenate, $50 \mu$ l of washed EZView Red anti-Flag M2 affinity gel (Sigma-Aldrich) and $45 \mu \mathrm{l}$ of anti-Myc antibody (Novus Biologicals) coupled to magnetic beads ( $3 \mu \mathrm{g}$ of Myc antibody for every 5 $\mu \mathrm{l}$ of magnetic beads) (Dynabeads M-280 Tosylactivated; Invitrogen) were added. The homogenate/antibody mixture was gently rotated overnight at $4^{\circ} \mathrm{C}$. After the overnight incubation, the Myc magnetic beads were separated from the homogenate/antibody mixture using a magnetic particle concentrator (Invitrogen), and then the Flag affinity gels were separated by centrifugation. The Myc magnetic beads and Flag affinity gels were washed with $1 \times$ PBS three times. After the final wash, $30 \mu \mathrm{l}$ of sample buffer was added, and samples were boiled for $2 \mathrm{~min}$.

Flag IP, Myc IP and total striatal samples were loaded onto $4-12 \%$ polyacrylamide Bis-Tris gels (Bio-Rad), separated by electrophoresis, and transferred to nitrocellulose membranes $(0.2 \mu \mathrm{M})$ (Schleicher and Schuell).

Preparation of striatal tissues for analysis of protein phosphorylation in vivo. Mice were injected intraperitoneally with rolipram $(10 \mathrm{mg} / \mathrm{kg})$, papaverine $(30 \mathrm{mg} / \mathrm{kg})$, or haloperidol $(0.1,0.3$, or $1.0 \mathrm{mg} / \mathrm{kg})$ or with vehicle control ( $5 \mathrm{ml} / \mathrm{kg}$ body weight). The vehicle for rolipram contained the following (final concentration): 5\% DMSO, 5\% Tween 20, $15 \%$ polyethylene glycol 400 (PEG 400 ), and $75 \%$ water. The vehicle for papaverine was saline, and the vehicle for haloperidol was acidified saline titrated to $\mathrm{pH}$ 5.5. At the indicated time points after injection, the mice were killed by focused microwave cranial irradiation $(4.5-5.0 \mathrm{~kW}$ for $1.3 \mathrm{~s}$ ) using a small animal microwave (Muromachi Kikai), which inactivates protein kinases and phosphatases to preserve in vivo levels of protein phosphorylation (O'Callaghan and Sriram, 2004). Striata were dissected from each mouse brain, frozen in liquid nitrogen, and stored at $-80^{\circ} \mathrm{C}$ until assayed.

Frozen samples of brain tissue were processed as described for slices. Equal amounts of protein $(15-30 \mu \mathrm{g})$ were loaded on $10 \%$ polyacrylamide BIS-Tris gels (Bio-Rad), separated by electrophoresis, and transferred to nitrocellulose membranes $(0.2 \mu \mathrm{M})$ (Schleicher and Schuell).

Immunoblotting. The membranes were immunoblotted using phosphorylation-state-specific antibodies raised against phospho-peptides: phospho-Thr34 DARPP-32, a site phosphorylated by PKA (CC500; 1:4000 dilution); phospho-Ser845 GluR1, a site phosphorylated by PKA (p1160-845; 1:250 dilution; PhosphoSolutions); phosphoThr202/Tyr204 ERK (1:2000 dilution; New England BioLabs); phosphoSer40 tyrosine hydroxylase, a site phosphorylated by PKA (AB5935; 1:1000 dilution; Millipore Bioscience Research Reagents); phospho-Ser6 synapsin I, a site phosphorylated by PKA and CaMKI (RU440; 1:6000 
dilution). Antibodies generated against DARPP-32 (C24-5a; 1:7500 dilution), GluR1 (E-6; 1:250 dilution; (Santa Cruz Biotechnology), ERK (1:1000 dilution; New England BioLabs), TH (TH-16; 1:10,000 dilution; Sigma), and synapsin I (G486; 1:5000 dilution), which are not phosphorylation-state-specific, were used to determine the total amount of proteins. None of the experimental manipulations used in the present study altered the total levels of specific phosphoproteins.

The membrane was incubated with a goat anti-mouse or rabbit Alexa 680-linked IgG (1:5000 dilution; Invitrogen) or a goat anti-mouse or rabbit IRDye800-linked IgG (1:5000 dilution; Rockland). Fluorescence at infrared wavelengths was detected by the Odyssey infrared imaging system (LI-COR) and quantified using Odyssey software. In an individual experiment, samples from control and drug-treated slices were analyzed on the same immunoblot. For each experiment, values obtained for slices were normalized to values for either the control or the drug-treated slices, as described in the figure legends. Normalized data from multiple experiments were averaged and statistical analysis was performed as described in the figure legends.

Immunohistochemistry. Under deep anesthesia induced with sodium pentobarbital, male C57BL/6 mice at 6-8 weeks old were perfused rapidly through the left ventricle with $50 \mathrm{ml}$ of $4 \%$ paraformaldehyde in 0.1 м phosphate buffer, $\mathrm{pH} 7.2$, at room temperature. Serial coronal sections $50 \mu \mathrm{m}$ in thickness were cut with a vibrating microtome, VT1000S (Leica Microsystems). Sections were processed for immunohistochemistry using the free-floating method, as described previously (Fukuda et al., 1996). Sections were incubated with a rabbit anti-PDE4B antibody (sc25812; 1:100; Santa Cruz Biotechnology), a rabbit anti-PDE10A antibody (101AP; 1:100-500 dilution; FabGennix), a mouse anti-DARPP-32 antibody (C24-5a; 1:20,000 dilution), a mouse anti-flag antibody (M2; 1:2000; Sigma), or a goat anti-Myc antibody (NB600-338; 1:10,000 dilution; Novus Biologicals) at $20^{\circ} \mathrm{C}$ for $7 \mathrm{~d}$. Antibody binding was visualized with a fluorescein isothiocyanate-conjugated donkey anti-rabbit or mouse IgG (1:100; Jackson ImmunoResearch) and a rhodamine redconjugated donkey anti-rabbit or goat IgG (1:100; Jackson ImmunoResearch). Sections were mounted in Vectashield (Vector Laboratories) and examined with a confocal laser-scanning microscope, LSM 5 PASCAL (Zeiss).

Analysis of the levels of dopamine and its metabolites in striatal tissue in vivo. Mice were injected intraperitoneally with rolipram $(10 \mathrm{mg} / \mathrm{kg}$, in $5 \%$ DMSO plus 5\% Tween 20 plus 15\% PEG 400 plus $75 \%$ water), papaverine $(30 \mathrm{mg} / \mathrm{kg}$, in saline), or haloperidol $(0.3 \mathrm{mg} / \mathrm{kg}$, in acidified saline titrated to $\mathrm{pH} 5.5$ ) or with vehicle solution ( $5 \mathrm{ml} / \mathrm{kg}$ body weight). Thirty minutes after injection, the mice were killed by focused microwave cranial irradiation as described above. Striata were dissected from each mouse brain, frozen in liquid nitrogen, and stored at $-80^{\circ} \mathrm{C}$ until assayed.

Dopamine and its metabolites were quantified by high-performance liquid chromatography with electrochemical detection (HPLC-EC; Waters). Tissues were homogenized in $300 \mu \mathrm{l}$ of ice-cold $0.2 \mathrm{M}$ perchloric acid, containing $1 \mu \mathrm{M}$ dihydroxybenzylamine as internal standard, and centrifuged at $10,000 \mathrm{~g}$ for $10 \mathrm{~min}$ at $4^{\circ} \mathrm{C}$. The supernatant was filtered through a $0.2 \mu \mathrm{m}$ membrane, and an aliquot $(10 \mu \mathrm{l})$ was injected from a temperature-controlled $\left(4^{\circ} \mathrm{C}\right)$ automatic sample injector (Waters 717 plus Autosampler) connected to a Waters 515 HPLC pump. Catecholamines were separated on a C18 reverse-phase column (LC-18 RP; Waters SYMMETRY, $25 \mathrm{~cm} \times 4.6 \mathrm{~mm} ; 5 \mu \mathrm{m}$ ), electrochemically detected (Waters 464 Pulsed Electrochemical Detector; range $10 \mathrm{nA}$, potential $+0.7 \mathrm{~V}$ ), and analyzed using Millennium software (Waters). The mobile phase, $\mathrm{pH}$ 3.0, for isocratic separation of dopamine consisted of dibasic sodium phosphate $(75 \mathrm{~mm})$, octane sulfonic acid $(1.7 \mathrm{~mm})$, acetonitrile $(10 \% \mathrm{v} / \mathrm{v})$, and EDTA $(25 \mu \mathrm{M})$. Flow rate was maintained at 1 $\mathrm{ml} / \mathrm{min}$. Dopamine, 3,4-dihydroxyphenylacetic acid (DOPAC), and homovanillic acid (HVA) standards $(0.5-25 \mathrm{pmol})$ were prepared in $0.2 \mathrm{M}$ perchloric acid containing dihydroxybenzylamine. Recovery of each analyte was adjusted with respect to the internal standard and quantified from a standard curve. The levels of dopamine and its metabolites were expressed as micrograms per gram of wet tissue.

\section{Results}

Effect of a PDE10A inhibitor, papaverine, and a PDE4 inhibitor, rolipram, on DARPP-32 Thr34, GluR1 Ser845, and ERK2 Thr202/Tyr204 phosphorylation in neostriatal slices

The phosphorylation of DARPP-32 at Thr34 (PKA site), GluR1 at Ser845 (PKA site), and ERK2 at Thr202/Tyr204 is known to play important roles in striatal neurons (Svenningsson et al., 2004; Girault et al., 2007). We therefore examined the effects of rolipram and papaverine on the phosphorylation of these substrates in neostriatal slices. Treatment of mouse neostriatal slices with papaverine for $60 \mathrm{~min}$ increased the levels of phospho-Thr34 DARPP-32, phospho-Ser845 GluR1, and phospho-Thr202/ Tyr204 ERK2 maximally at a concentration of $10 \mu \mathrm{M}$ by sevenfold, fivefold, and twofold, respectively, with a half-maximal effect at $\sim 300 \mathrm{~nm}$ (Fig. $1 A-C$, left and center panels). Papaverine at $1 \mu \mathrm{M}$ induced maximal changes in DARPP-32, GluR1, and ERK2 phosphorylation by $60 \mathrm{~min}$ of incubation (Fig. $1 A-C$, right panels).

Treatment of neostriatal slices with rolipram for $60 \mathrm{~min}$ increased the levels of phospho-Thr34 DARPP-32 and phosphoSer845 GluR1 at a high concentration of $100 \mu \mathrm{M}$ by approximately twofold, but not significantly at lower concentrations (Fig. $1 A, B$, left and center panels). In the analysis of the time course, rolipram at $10 \mu \mathrm{M}$ slightly increased DARPP-32 Thr34 phosphorylation at 2 min of incubation and GluR1 Ser845 phosphorylation at 30 and $60 \mathrm{~min}$. Treatment with rolipram increased ERK2 Thr202/Tyr204 phosphorylation in a dose- and timedependent manner similar to that seen with papaverine (Fig. 1C).

These results clearly demonstrate that the effects of the PDE10A inhibitor, papaverine, on the phosphorylation of postsynaptic PKA substrates in striatal neurons, DARPP-32 $(p<$ 0.01 for both dose-response and time course, two-way ANOVA) and GluR1 $(p<0.01$ for both dose-response and time course, two-way ANOVA), were much larger than those of the PDE4 inhibitor, rolipram.

\section{Effect of papaverine and rolipram on TH Ser40 and synapsin I Ser9 phosphorylation in neostriatal slices}

We next examined the effect of papaverine and rolipram on the phosphorylation of presynaptic PKA substrates, TH at Ser40 and synapsin I at Ser9, which are known to play an important role in the synthesis of dopamine (Harada et al., 1996; Dunkley et al., 2004) and the release of neurotransmitters (Fiumara et al., 2004), respectively. Treatment with rolipram for $60 \mathrm{~min}$ increased the levels of phospho-Ser40 TH and phospho-Ser9 synapsin I maximally at a concentration of $10 \mu \mathrm{M}$ by threefold and fourfold, respectively, with a half-maximal effect of $\sim 100 \mathrm{~nm}$ (Fig. $2 A, B$, left and center panels). Rolipram at $10 \mu \mathrm{M}$ induced a maximal effect on TH Ser40 and synapsin I Ser9 phosphorylation within 10 min of incubation (Fig. $2 A, B$, right panels).

Treatment with papaverine at a high concentration of $10 \mu \mathrm{M}$ for $60 \mathrm{~min}$ increased the levels of phospho-Ser40 $\mathrm{TH}$ and phospho-Ser9 synapsin I by approximately twofold, but not at lower concentrations (Fig. $2 A, B$, left and center panels). Papaverine at $1 \mu \mathrm{M}$ did not affect TH Ser40 and synapsin I Ser9 phosphorylation at any incubation time (Fig. $2 A, B$, right panels). The effects of the PDE4 inhibitor, rolipram, on the phosphorylation of TH $(p<0.01$ for both dose-response and time course, twoway ANOVA) and synapsin I ( $p<0.01$ for both dose-response and time course, two-way ANOVA) were much larger than those of the PDE10A inhibitor, papaverine.

These results suggest that the inhibition of PDE10A by papaverine induces activation of CAMP/PKA signaling in medium 


\section{A. P-Thr34 DARPP-32}

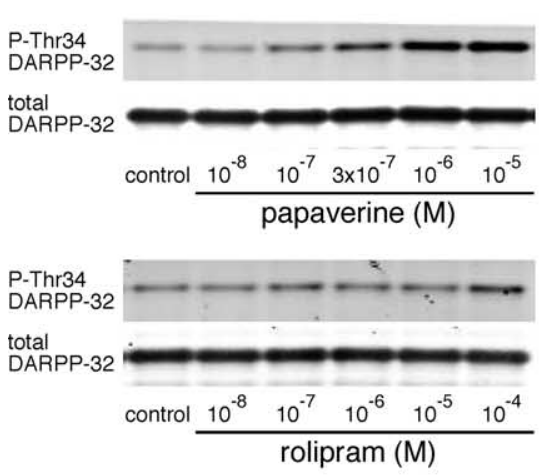

\section{B. P-Ser845 GluR1}

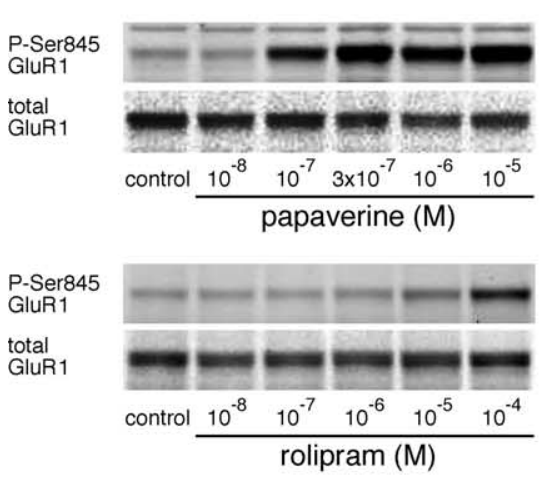

\section{P-ERK2}
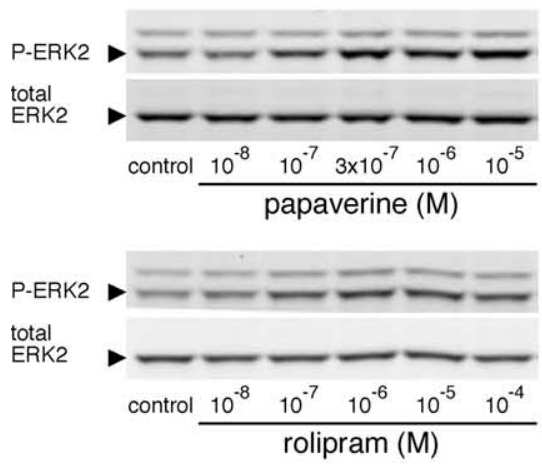
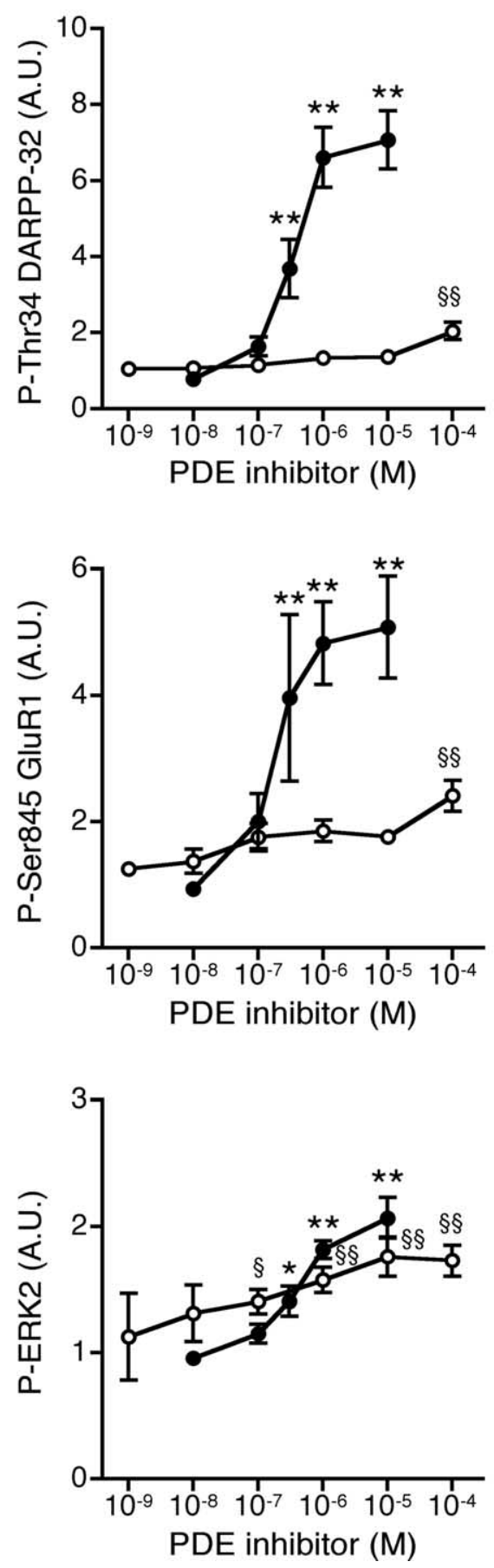
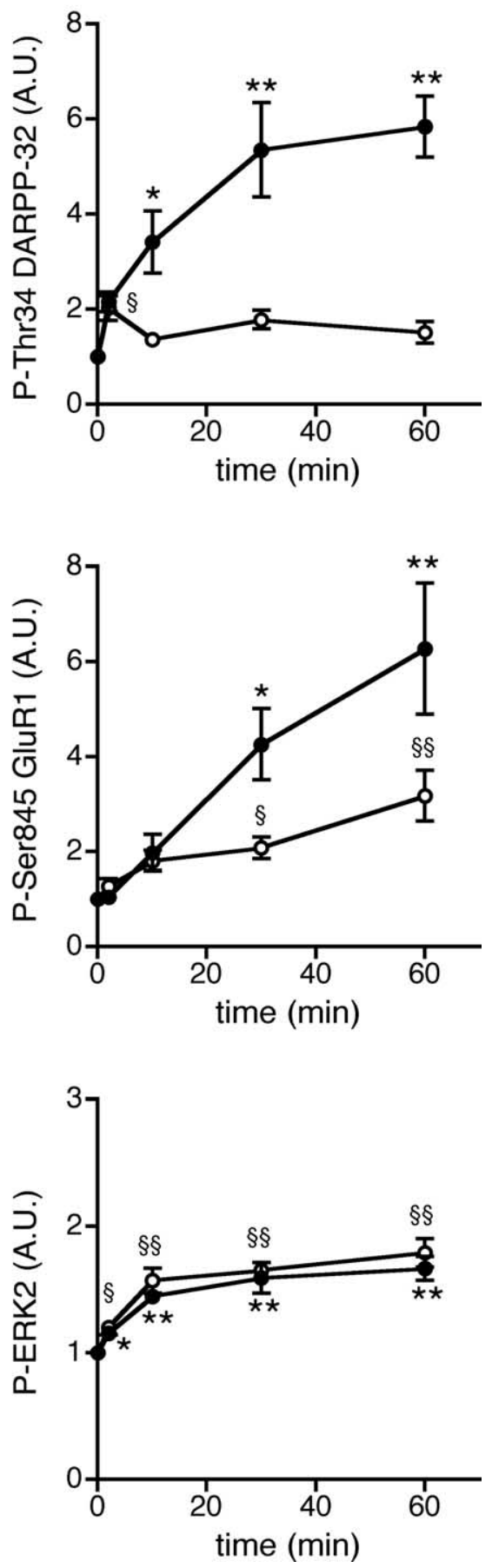

Figure 1. Effect of a PDE10A inhibitor, papaverine, and a PDE4 inhibitor, rolipram, on DARPP-32, GluR1, and ERK2 phosphorylation in neostriatal slices. A-C, Mouse neostriatal slices were treated with various concentrations of papaverine (closed circles) or rolipram (open circles) for $60 \mathrm{~min}$ (left and center panels) and with papaverine (1 $\mu \mathrm{m}$; closed circles) or rolipram (10 $\mu \mathrm{m}$; open circles) for the indicated times (right panels). Changes in the phosphorylation of DARPP-32 at Thr34 (the PKA site), GluR1 at Ser845 (the PKA site), and ERK at Thr202/Tyr204 (the MEK site) were determined by Western blotting using phosphorylation-state-specific antibodies. Typical immunoblots are shown in left panels. Data represent means \pm SEM for $5-13$ experiments. ${ }^{*} p<0.05,{ }^{* *} p<0.01$ compared with untreated slices for papaverine; ${ }^{\S} p<0.05,{ }^{\S \S} p<0.01$ compared with untreated slices for rolipram; one-way ANOVA followed by Newman-Keuls test.

spiny neurons, leading to the phosphorylation of DARPP-32 and GluR1, and that the inhibition of PDE4 by rolipram induces activation of cAMP/PKA signaling mainly at presynaptic, dopaminergic terminals, leading to the phosphorylation of TH and synapsin I. ERK2 is likely expressed both in medium spiny neurons and at dopaminergic terminals, and therefore, ERK2 phosphorylation is similarly affected by papaverine and rolipram.
PDE10A regulates dopamine $D_{1}$ receptor, dopamine $D_{2}$ receptor, and adenosine $A_{2 A}$ receptor signaling in neostriatal neurons

Dopamine $D_{1}$ and adenosine $A_{2 A}$ receptors couple to $G_{\text {olf }}$ and stimulate cAMP synthesis by adenylyl cyclase in striatonigral and striatopallidal neurons, respectively (Nishi et al., 1997; Hervé et al., 2001; Yabuuchi et al., 2006). To evaluate the contribution of 


\section{A. P-Ser40 tyrosine hydroxylase (TH)}

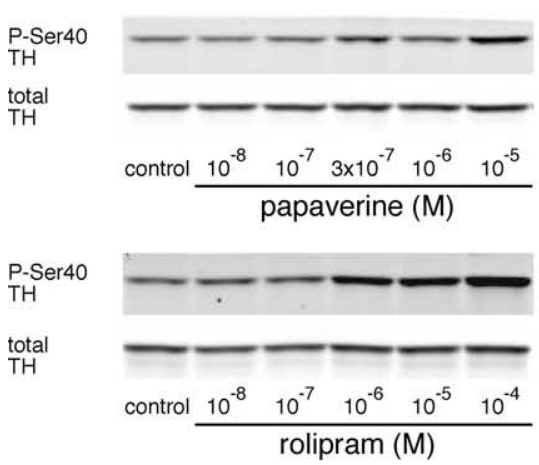

\section{B. P-Ser9 synapsin I}

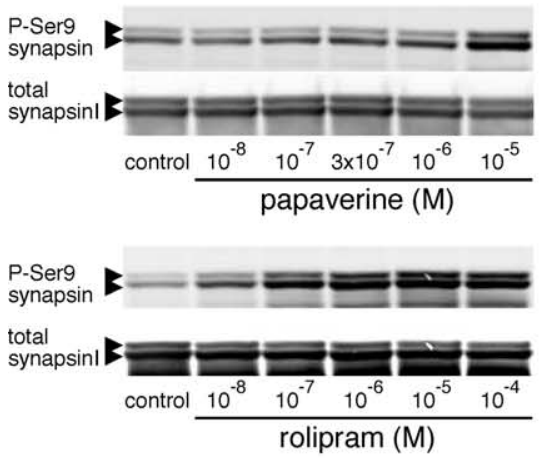

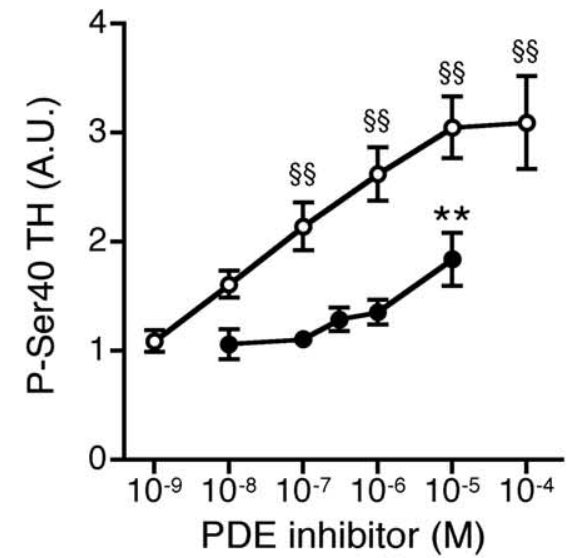
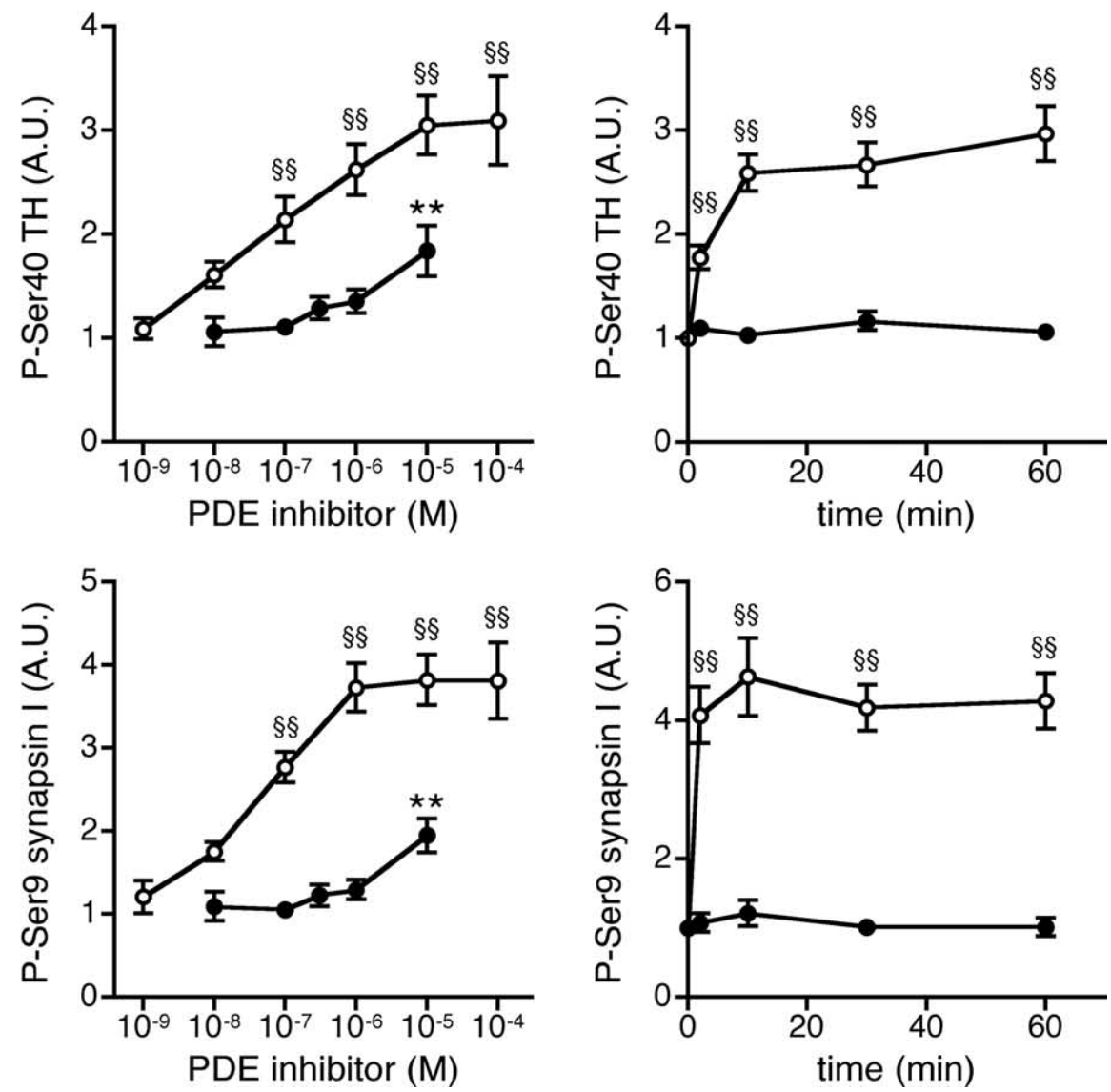

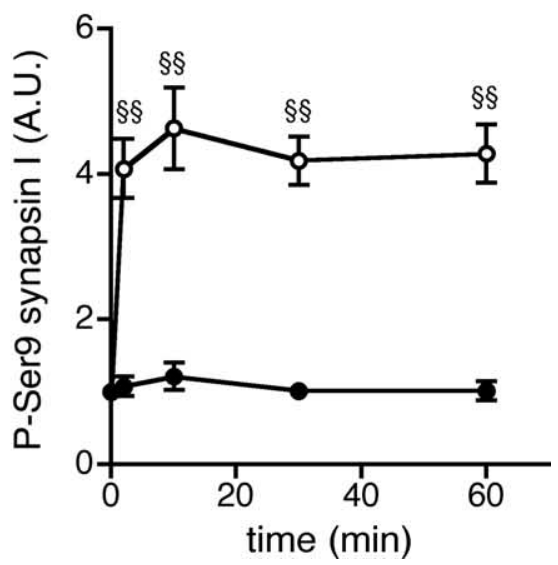

Figure 2. Effect of papaverine and rolipram on TH and synapsin I phosphorylation in neostriatal slices. A-C, Mouse neostriatal slices were treated with various concentrations of papaverine (closed circles) or rolipram (open circles) for $60 \mathrm{~min}$ (left and center panels) and with papaverine ( $1 \mu \mathrm{m}$; closed circles) or rolipram (10 $\mu \mathrm{m}$; open circles) for the indicated times (right panels). Changes in the phosphorylation of TH at Ser40 (the PKA site) and synapsin I at Ser9 (the PKA/CaMKI site), which are selectively expressed at presynaptic terminals, were determined by Western blotting using phosphorylation-state-specific antibodies. Typical immunoblots are shown in left panels. Data represent means \pm SEM for $5-13$ experiments. ${ }^{* *} p<0.01$ compared with untreated slices for papaverine; ${ }^{\S \S} p<0.01$ compared with untreated slices for rolipram; one-way ANOVA followed by Newman-Keuls test.

dopamine $\mathrm{D}_{1}$ and adenosine $\mathrm{A}_{2 \mathrm{~A}}$ receptor signaling to the papaverine-induced increase in DARPP-32 Thr34 phosphorylation, the effect of papaverine was examined in the presence of a dopamine $\mathrm{D}_{1}$ receptor antagonist, $\mathrm{SCH} 23390$, or an adenosine $\mathrm{A}_{2 \mathrm{~A}}$ receptor antagonist, ZM241385 (Fig. 3A). The papaverineinduced increase in DARPP-32 Thr34 phosphorylation was attenuated both by SCH23390 and by ZM241385. However, the papaverine-induced increase was not affected by an inhibitor of soluble guanylyl cyclase, ODQ, indicating that papaverine did not activate cGMP/protein kinase G (PKG) signaling (Siuciak et al., 2006b) coupled to DARPP-32 Thr34 phosphorylation in this slice preparation (Nishi et al., 2005).

We next examined the effect of a dopamine $\mathrm{D}_{1}$ receptor agonist, SKF81297 $(1 \mu \mathrm{M})$, and an adenosine $\mathrm{A}_{2 \mathrm{~A}}$ receptor agonist, CGS21680 ( $5 \mu \mathrm{M})$, on DARPP-32 Thr34 phosphorylation in the absence or presence of papaverine (Fig. $3 B$ ). The effects of SKF81297 and CGS21680 on DARPP-32 Thr34 phosphorylation were enhanced by papaverine. These results suggest that PDE10A regulates both dopamine $\mathrm{D}_{1}$ receptor-stimulated cAMP/PKA signaling in striatonigral neurons and adenosine $\mathrm{A}_{2 \mathrm{~A}}$ receptorstimulated cAMP/PKA signaling in striatopallidal neurons.

Dopamine $\mathrm{D}_{2}$ receptors are expressed in striatopallidal neurons, couple to $G_{i}$, and thereby inhibit cAMP/PKA signaling in striatopallidal neurons (Nishi et al., 1997). Because dopamine $\mathrm{D}_{2}$ receptors play a central role in the regulation of psychomotor functions by dopamine, the role of PDE10A in dopamine $\mathrm{D}_{2}$ receptor signaling was examined (Fig. $3 C$ ). Treatment with a dopamine $\mathrm{D}_{2}$ receptor agonist, quinpirole, decreased the level of phospho-Thr34 DARPP-32 to 50\% of control, whereas treatment with a dopamine $\mathrm{D}_{2}$ receptor antagonist, raclopride, did not affect DARPP-32 Thr34 phosphorylation. Treatment with papaverine $(10 \mu \mathrm{M})$ increased DARPP-32 Thr34 phosphorylation by 14 -fold. In the presence of papaverine, quinpirole failed to decrease the level of phospho-Thr34 DARPP-32. These results suggest that the PDE10A inhibitor, papaverine, attenuates the effect of a dopamine $\mathrm{D}_{2}$ receptor agonist in striatopallidal neurons. The inhibitory effect of quinpirole on TH Ser40 phosphorylation was not attenuated by papaverine at dopaminergic terminals (data not shown), where papaverine has little effect.

\section{PDE4 regulates adenosine $A_{2 A}$ receptor signaling in} striatopallidal neurons

A possible role of PDE4 in dopamine $\mathrm{D}_{1}$ receptor and adenosine $A_{2 A}$ receptor signaling in striatal neurons was examined. Treatment of slices with rolipram $(100 \mu \mathrm{M})$ slightly increased the level of phospho-Thr34 DARPP-32, but the effect was not statistically significant in this series of experiments (Fig. 4). Both CGS21680 $(5 \mu \mathrm{M})$ and SKF81297 (1 $\mu \mathrm{M})$ increased DARPP-32 Thr34 phos- 
A.

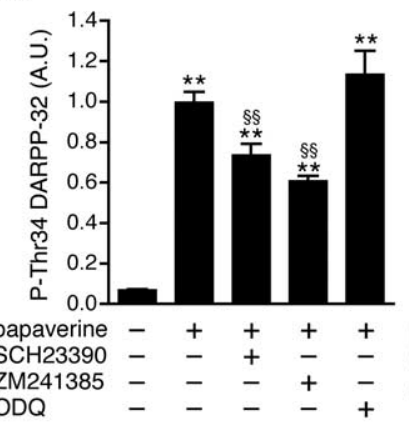

B.

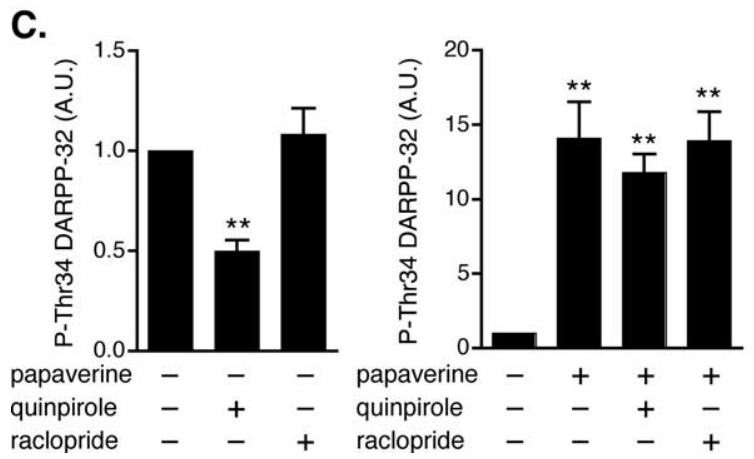

Figure 3. Effect of papaverine on dopamine $D_{1}$, dopamine $D_{2}$, and adenosine $A_{2 A}$ receptor signaling in neostriatal slices. $A$, The effect of papaverine ( $10 \mu \mathrm{m}$ for $60 \mathrm{~min}$ ) on DARPP-32 Thr34 phosphorylation was examined in the presence of a dopamine $D_{1}$ receptor antagonist, SCH23390 (1 $\mu \mathrm{M}$ for $60 \mathrm{~min}$ ), an adenosine $A_{2 A}$ receptor antagonist, ZM241385 (1 $\mu \mathrm{M}$ for 60 $\mathrm{min})$, or an inhibitor of soluble guanylyl cyclase, ODQ (10 $\mu \mathrm{m}$ for $60 \mathrm{~min})$. Data represent means \pm SEM for $4-6$ experiments. $\boldsymbol{B}$, In slices pretreated with papaverine ( $10 \mu \mathrm{m}$ for $60 \mathrm{~min})$ and adenosine deaminase (30 $\mu \mathrm{g} / \mathrm{ml}$ for $60 \mathrm{~min}$ ), the effects of a dopamine $D_{1}$ agonist, SKF81297 ( $1 \mu \mathrm{M}$ for $5 \mathrm{~min}$ ) and an adenosine $\mathrm{A}_{2 \mathrm{~A}}$ receptor agonist, CGS21680 (5 $\mu \mathrm{m}$ for $2 \mathrm{~min}$ ), on DARPP-32 Thr34 phosphorylation were examined. Adenosine deaminase, additionally included in the incubation medium to decease tissue content of adenosine, reduced the basal and papaverine-induced levels of phospho-Thr34 DARPP-32. Data represent means \pm SEM for 6-19 experiments. $C$, The effect of a dopamine $D_{2}$ receptor agonist, quinpirole $(1 \mu \mathrm{M}$ for 10 $\mathrm{min})$, and a dopamine $\mathrm{D}_{2}$ receptor antagonist, raclopride (1 $\mu \mathrm{m}$ for $\left.10 \mathrm{~min}\right)$, on DARPP-32 Thr34 phosphorylation was examined in the absence (left) or presence (right) of papaverine (10 $\mu \mathrm{M}$ for $70 \mathrm{~min})$. Data represent means \pm SEM for $7-13$ experiments. ${ }^{* *} p<0.01$ compared with control; $;{ }^{\S} p<0.01$ compared with papaverine alone; ${ }^{+\dagger} p<0.01$ compared with CGS21680 alone; ${ }^{\text {"q9 }} p<0.01$ compared with SKF81297 alone; one-way ANOVA followed by NewmanKeuls test.

phorylation by approximately fourfold. Rolipram enhanced the stimulatory effect of CGS21680 on DARPP-32 Thr34 phosphorylation, but not that of SKF81297. These results suggest that PDE4 preferentially regulates adenosine $\mathrm{A}_{2 \mathrm{~A}}$ receptor-stimulated cAMP/PKA signaling in striatopallidal neurons, in addition to cAMP/PKA signaling at dopaminergic terminals (Fig. 2).

\section{Expression patterns of PDE10A and PDE4B in}

\section{striatal neurons}

The expression patterns of PDE10A and PDE4B in striatal neurons were analyzed by immunohistochemistry. DARPP-32 was used as a marker of medium spiny neurons (Ouimet et al., 1992). The expression of PDE10A was detected in all DARPP-32positive striatal neurons (Fig. 5A), and a punctate pattern of PDE10A staining was observed. Strong immunoreactivity of PDE4B was detected in a subset of DARPP-32-positive neurons (Fig. 5B).

To determine the subset of medium spiny neurons that expresses PDE4B, PDE4B expression was analyzed using neostriatal tissues from D1-DARPP-32-Flag/D2-DARPP-32-Myc mice. In

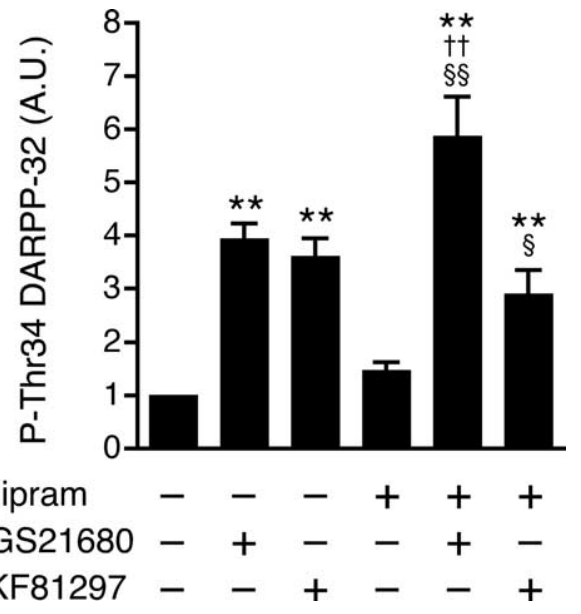

Figure 4. Effect of rolipram on dopamine $D_{1}$ and adenosine $A_{2 A}$ receptor signaling in neostriatal slices. In slices pretreated with rolipram ( $100 \mu \mathrm{m}$ for $60 \mathrm{~min})$, the effects of a dopamine $D_{1}$ agonist, SKF81297 (1 $\mu \mathrm{m}$ for $5 \mathrm{~min}$ ), and an adenosine $A_{2 A}$ receptor agonist, CGS21680 (5 $\mu \mathrm{M}$ for $2 \mathrm{~min}$ ), on DARPP-32 Thr34 phosphorylation were examined. Data represent means \pm SEM for $6-19$ experiments. ${ }^{* *} p<0.01$ compared with control; ${ }^{\S} p<0.05$, ${ }^{\$ \S} p<0.01$ compared with rolipram alone; ${ }^{\dagger \dagger} p<0.01$ compared with CGS21680 alone; one-way ANOVA followed by Newman-Keuls test.

these mice, Flag-tagged DARPP-32 is expressed in striatonigral neurons, and Myc-tagged DARPP-32 is expressed in striatopallidal neurons (Bateup et al., 2008). In confirmation of a previous report (Bateup et al., 2008), there was no overlap of the expression of Flag-tagged and Myc-tagged DARPP-32 (Fig. 6A). In this study, we found that the expression of PDE4B was higher in Myc-positive striatopallidal neurons than in Flag-positive striatonigral neurons (Fig. 6B, $C$ ).

\section{Regulation of DARPP-32 Thr34 phosphorylation in} striatonigral and striatopallidal neurons by papaverine and rolipram

Neuronal type-specific regulation of DARPP-32 Thr34 phosphorylation by papaverine and rolipram was investigated using neostriatal slices from $D_{1}$-DARPP-32-Flag/ $D_{2}-D A R P P-32-M y c$ mice. Flag- and Myc-tagged DARPP-32 ( $\mathrm{D}_{1}$-Flag and $\mathrm{D}_{2}$-Myc) was immunoprecipitated from $\mathrm{D}_{1}$ receptor-enriched striatonigral and $\mathrm{D}_{2}$ receptor-enriched striatopallidal neurons, respectively, and the phosphorylation states of DARPP-32 at Thr34 in the two types of neurons were analyzed (Fig. 7). Treatment of neostriatal slices from $D_{1}$-DARPP-32-Flag/ $D_{2}$-DARPP-32-Myc mice with papaverine $(10 \mu \mathrm{M})$ increased the level of phosphoThr34 DARPP-32 by approximately sevenfold in total striatal homogenate. Papaverine increased the levels of phospho-Thr34 Flag- and Myc-tagged DARPP-32 by twofold and sixfold, respectively. Treatment of slices with rolipram $(100 \mu \mathrm{M})$ increased the level of phospho-Thr34 DARPP-32 by $\sim 1.9$-fold in total striatal homogenate. Rolipram increased the levels of phospho-Thr34 Flag- and Myc-tagged DARPP-32 by 2.2-fold and 2.6-fold, respectively. We analyzed the relative stoichiometry of the phosphorylation of Flag- and Myc-tagged DARPP-32 at Thr34 in slice preparations under basal conditions, and found that the Thr34 phosphorylation of Myc-tagged DARPP-32 was $\sim 4.5$-fold higher than that of Flag-tagged DARPP-32. Taking this stoichiometry into consideration, the phosphorylated level of DARPP-32 at Thr34 is 13.5-fold higher after papaverine treatment, and 5.3fold higher after rolipram treatment, in the striatopallidal compared with the striatonigral neurons. 
Effect of papaverine and rolipram on TH phosphorylation at presynaptic dopaminergic terminals in vivo

The role of PDE10A and PDE4 in the regulation of the phosphorylation state of the presynaptic PKA substrate, TH at Ser40, was examined in intact animals. A single injection of papaverine $(30 \mathrm{mg} / \mathrm{kg}$, i.p.) or rolipram $(10 \mathrm{mg} / \mathrm{kg}$, i.p.) did not affect the basal level of phospho-Ser40 phosphorylation (Fig. 8A) up to $60 \mathrm{~min}$ after intraperitoneal injection. We examined whether either of these phosphodiesterase inhibitors might potentiate the ability of a neuroleptic compound to elevate $\mathrm{TH}$ phosphorylation state at Ser40. A dose-response study shown in Figure $8 A$ (inset) revealed that the neuroleptic drug, haloperidol, induced a submaximal increase in TH Ser40 phosphorylation at a concentration of $0.3 \mathrm{mg} / \mathrm{kg}$, i.p. Rolipram (Fig. $8 C$ ), but not papaverine (Fig. $8 B$ ), enhanced the haloperidol-induced increase in TH Ser40 phosphorylation.

\section{Effect of papaverine and rolipram on} GluR1 phosphorylation in striatal neurons in vivo

The role of PDE10A and PDE4 in the regulation of the phosphorylation state of the postsynaptic PKA substrate, GluR1 at Ser845, was examined in intact animals. The basal level of phospho-Ser845 GluR1 was increased maximally by 2.3 -fold at 15 min after a single injection of papaverine (30 mg/kg, i.p.). Rolipram (10 mg/kg, i.p.), given as a single injection, induced a much smaller effect on the level of phosphoSer845 GluR1 at $30 \mathrm{~min}$ after injection (Fig. $8 D$ ). The effects of papaverine and rolipram were examined in combination with haloperidol. Haloperidol $(0.3 \mathrm{mg} / \mathrm{kg}$, i.p.) alone increased GluR1 Ser845 phosphorylation by $\sim 1.5$-fold. Papaverine clearly potentiated the haloperidolinduced increase in GluR1 Ser845 phosphorylation, increasing levels to $\sim 3$.4-fold (Fig. $8 E$ ). In contrast to the effect of papaverine, rolipram induced only a small additional effect on the GluR1 Ser845 phosphorylation, enhancing the haloperidol-induced increase from $\sim 1$.4fold to $\sim 1.7$-fold (Fig. $8 F$ ). Phosphorylation of DARPP-32 was also analyzed, but changes in DARPP-32 Thr34 phosphorylation were not detected in response to papaverine, rolipram and haloperidol alone, or in combination (data not shown).

These results in vivo demonstrate that the inhibition of PDE4 by rolipram predominantly enhances haloperidol-induced activation of cAMP/PKA signaling at dopaminergic terminals, leading to $\mathrm{TH}$ Ser40 phosphorylation, and that the inhibition of
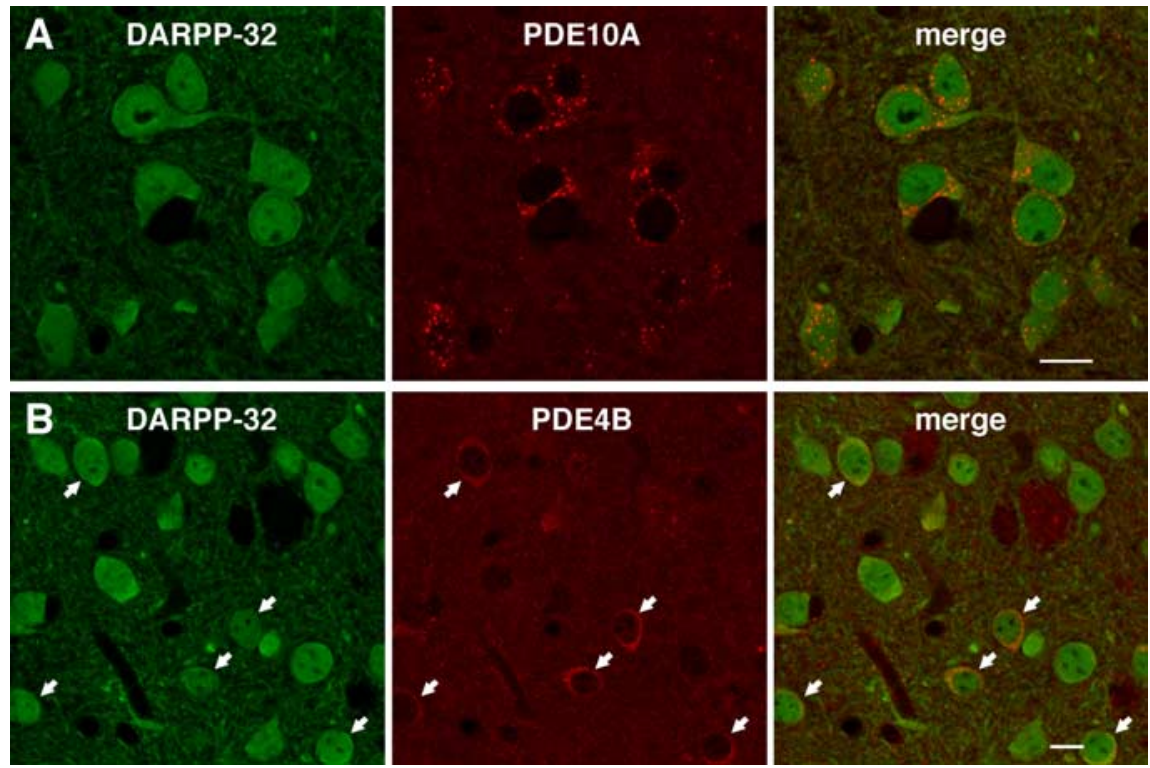

Figure 5. Expression of PDE4B and PDE10A in the striatum. $A, B$, Double immunostaining of striatal tissues with (A) DARPP-32 and PDE10A antibodies and (B) DARPP-32 and PDE4B antibodies. Arrows in $\boldsymbol{B}$ indicate DARPP-32-positive neurons with strong PDE4B immunoreactivity. Scale bars, $10 \mu \mathrm{m}$.
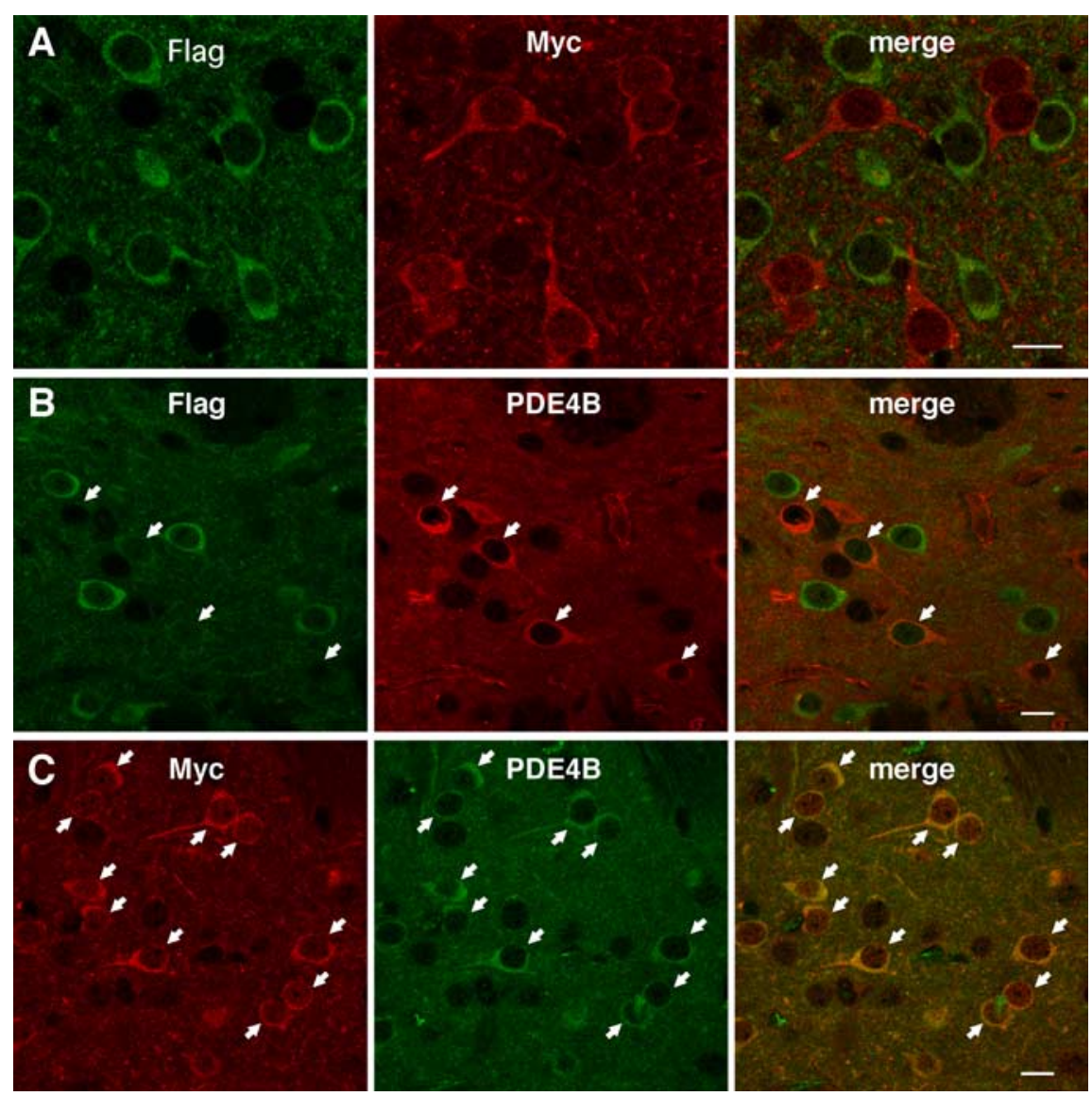

Figure 6. High expression of PDE4B in Myc-positive, striatopallidal neurons in the striatum of $D_{1}-D A R P P-32-F l a g / D_{2}-D A R P P-$ 32-Myc mutant mice. A, Expression of Flag- and Myc-tagged DARPP-32 in striatonigral and striatopallidal neurons, respectively, in the striatum of $D_{1}$-DARPP-32-Flag/ $D_{2}-D A R P P-32-M y c$ mutant mice. $B$, Double immunostaining of striatal tissues from $D_{1}$ DARPP-32-Flag/D ${ }_{2}-D A R P P-32-M y c$ mice with Flag and PDE4B antibodies. C, Double immunostaining of striatal tissues from $D_{1}$-DARPP-32-Flag/D, -DARPP-32-Myc mice with Myc and PDE4B antibodies. Striatal neurons with strong PDE4B immunoreactivity, indicted by arrows, correspond to Myc-positive, striatopallidal neurons. Scale bars, $10 \mu \mathrm{m}$. 

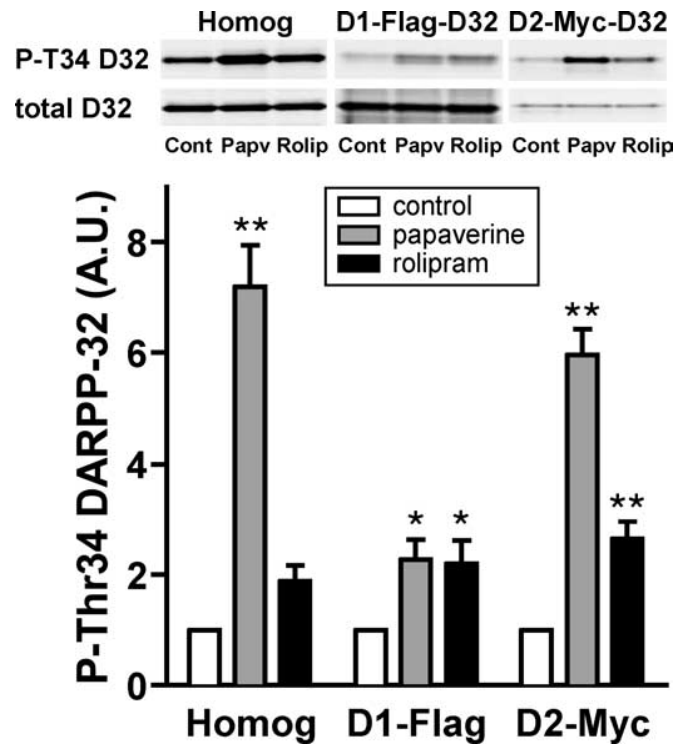

Figure 7. Neuronal type-specific regulation of DARPP-32 phosphorylation by papaverine and rolipram in neostriatal slices from $D_{1}$-DARPP-32-Flag/D ${ }_{2}$-DARPP-32-Myc mice. Neostriatal slices from $D_{1}$-DARPP-32-Flag/ $D_{2}$-DARPP-32-Myc mice were incubated with papaverine (10 $\mu \mathrm{M})$ or rolipram $(100 \mu \mathrm{M})$ for $60 \mathrm{~min}$. Flag-tagged DARPP-32, expressed in $D_{1}$ receptorenriched striatonigral neurons, and Myc-tagged DARPP-32, expressed in $D_{2}$ receptor-enriched striatopallidal neurons, were immunoprecipitated. The figure shows data from total striatal homogenate (Homog), Flag-tagged DARPP-32 in striatonigral neurons ( $D_{1}$-Flag), and Myctagged DARPP-32 in striatopallidal neurons ( $\mathrm{D}_{2}$-Myc). Typical immunoblots for detection of phospho-Thr34 DARPP-32 (P-T34 D32) and total DARPP-32 (total D32) in the same membrane are shown at the top. The levels of phospho-Thr34 DARPP-32 and total DARPP-32 were quantified by the 0 dyssey infrared imaging system, and the data (phospho-Thr34 DARPP-32/total DARPP-32) were normalized to values obtained with untreated slices. Data represent means \pm SEM for four experiments. ${ }^{*} p<0.05,{ }^{* *} p<0.01$ compared with control; one-way ANOVA followed by Newman-Keuls test.

PDE10A by papaverine selectively enhances haloperidol-induced activation of cAMP/PKA signaling in striatal neurons, leading to GluR1 Ser845 phosphorylation.

\section{Effect of papaverine and rolipram on dopamine metabolism} in the striatum in vivo

We examined whether the enhancement of haloperidol-induced $\mathrm{TH}$ phosphorylation by rolipram reflects a functional effect of the inhibitor on dopamine synthesis and turnover in the striatum in vivo. The effect of the drug on the rate of dopamine metabolism was quantitated by measuring the relative tissue concentrations of dopamine and its major metabolites, DOPAC and HVA in the striatum (Table 1). An increase in the ratio of DOPAC/dopamine and/or HVA/dopamine indicates an increase in striatal dopamine biosynthesis. A single injection of rolipram (10 mg/kg, i.p.) or papaverine $(30 \mathrm{mg} / \mathrm{kg}$, i.p.) per se did not affect the tissue content of dopamine, DOPAC, or HVA or the ratio of DOPAC/ dopamine or HVA/dopamine. Haloperidol ( $0.3 \mathrm{mg} / \mathrm{kg}$, i.p.) increased the tissue content of DOPAC and HVA and the ratios of DOPAC/dopamine and HVA/dopamine, as previously reported (Boyar and Altar, 1987). Rolipram further enhanced the haloperidol-induced increase in DOPAC content and DOPAC/ dopamine ratio, but did not affect the haloperidol-induced increase in HVA content or HVA/dopamine ratio. Papaverine did not affect the haloperidol-induced increase in DOPAC content or DOPAC/dopamine ratio, but slightly reduced the haloperidolinduced increase in HVA content and HVA/dopamine ratio. The results suggest that PDE4 plays a functional role in modulating do- pamine synthesis and the turnover of dopamine to DOPAC at dopaminergic terminals in response to haloperidol administration.

\section{Discussion}

The present study demonstrates that PDE10A and PDE4 are differentially expressed in neuronal subtypes in the striatum and play distinct roles in dopaminergic neurotransmission (see Fig. 9). PDE4 predominantly regulates cAMP/PKA signaling at dopaminergic terminals in the striatum. The inhibition of PDE4 by rolipram increases $\mathrm{TH}$ phosphorylation and dopamine synthesis, leading to an increase in dopaminergic tone. PDE4 also regulates cAMP/PKA signaling in medium spiny neurons, preferentially in striatopallidal neurons. In contrast, PDE10A exclusively regulates cAMP/PKA signaling in medium spiny neurons. The inhibition of PDE10A by papaverine activates cAMP/PKA signaling in medium spiny neurons comprising striatopallidal and striatonigral projections, leading to the inhibition of dopamine $\mathrm{D}_{2}$ receptor signaling in striatopallidal neurons and the potentiation of dopamine $\mathrm{D}_{1}$ receptor signaling in striatonigral neurons. Both PDE10A and PDE4 have been proposed as therapeutic targets for psychotic disorders (Menniti et al., 2006; Hebb and Robertson, 2007). Elucidation of the distinct roles of PDE10A and PDE4 in dopaminergic neurotransmission reveals the mechanisms by which selective PDE10A and PDE4 inhibitors may exert antipsychotic activity.

\section{Role of PDE10A in striatal neurons}

Using both pharmacological and genetic tools, we have shown that PDE10A regulates CAMP/PKA signaling in both striatopallidal and striatonigral neurons. In striatopallidal neurons, PDE10A inhibition by papaverine activated cAMP/PKA signaling by simultaneously potentiating adenosine $\mathrm{A}_{2 \mathrm{~A}}$ receptor signaling and inhibiting dopamine D2 receptor signaling. In striatonigral neurons, PDE10A inhibition by papaverine also activated cAMP/ PKA signaling, leading to the potentiation of dopamine $\mathrm{D}_{1}$ receptor signaling. PDE10A inhibition had greater effects on signaling in striatopallidal neurons. This observation was unanticipated because immunocytochemical data clearly show PDE10A to be abundant in most medium spiny neurons (Figs. 5, 6). The basis for the predominant effect of papaverine in striatopallidal cells is unclear. One possible explanation is that tonic activity of adenosine $A_{2 A}$ receptor signaling may have contributed to the large effects observed in striatopallidal cells, although adenosine deaminase was included during preincubation of slices. Alternatively, there may be functional differences in PDE10A inhibition in the two medium spiny cell populations that reflect subtle differences in PDE10A abundance or PDE10A subcellular targeting of PDE10A within striatopallidal and striatonigral neurons. More detailed neuroanatomical studies would be needed to resolve this issue.

The present study suggests that PDE10A exerts preferential effects on cAMP-mediated, relative to cGMP-mediated, signaling in striatal neurons. For example, although PDE10A is reported to hydrolyze cAMP and cGMP with near equal affinity (Bender and Beavo, 2006; Siuciak et al., 2006b), papaverine had no effect on the modulation of cGMP/PKG/phospho-Thr34 DARPP-32 signaling (Fig. 3A). Thus, the PDE10A inhibitor appears to effectively counteract dopamine $\mathrm{D}_{2}$ receptor signaling in striatopallidal neurons and potentiate dopamine $\mathrm{D}_{1}$ receptor signaling in striatonigral neurons mainly via cAMP-mediated effects.

Under in vivo conditions, papaverine stimulates cAMP/PKA signaling, leading to the phosphorylation of GluR1 at Ser845 in striatal neurons (Fig. 8D), as observed in slice preparations. It is 
likely that the ability of papaverine to activate cAMP/PKA signaling is suppressed by high dopamine $\mathrm{D}_{2}$ tone, because the effect of papaverine was enhanced in the presence of a typical antipsychotic, haloperidol (Fig. $8 E$ ). Haloperidol treatment has recently been shown to activate CAMP/PKA signaling selectively in striatopallidal neurons by inhibiting dopamine $\mathrm{D}_{2}$ receptors (Bateup et al., 2008). It is noteworthy that the PDE10A inhibitor and the antipsychotic drug inhibit dopamine $\mathrm{D}_{2}$ receptor signaling by different mechanisms and act synergistically to affect phosphoproteins.

In agreement with our results, inhibition of PDE10A by papaverine was previously shown to increase the phosphorylation of CREB and ERK by activating cAMP/PKA signaling in the striatum (Siuciak et al., 2006b). In a behavioral analysis, papaverine treatment (Siuciak et al., 2006b; Becker and Grecksch, 2008) or disruption of the PDE10A gene (Siuciak et al., 2006a) reduced spontaneous locomotor activity, phencyclidine-stimulated locomotor activity, and conditioned avoidance responding. Because inhibition of conditioned avoidance responding serves as a sensitive measure of antipsychotic activity of drugs (Wadenberg and Hicks, 1999), PDE10A inhibitors have been proposed as therapeutic reagents for schizophrenia (Hebb and Robertson, 2007; Menniti et al., 2007). The pharmacological profile of the PDE10A inhibitor, papaverine, to counteract dopamine $\mathrm{D}_{2}$ receptor signaling and potentiate dopamine $\mathrm{D}_{1}$ receptor signaling, resembles that of atypical antipsychotics, and therefore supports the idea that PDE10A inhibition would be expected to address the symptoms and cognitive deficits of psychosis.

Role of PDE4 at dopaminergic terminals This study demonstrates an important role for PDE4 in the regulation of cAMP/PKA signaling at dopaminergic terminals in the striatum. Inhibition of PDE4 activity by rolipram increased the state of phosphorylation of TH at Ser40 in neostriatal slices. In contrast, under in vivo conditions, inhibition of PDE4 by rolipram alone was insufficient to induce the phosphorylation of $\mathrm{TH}$ at Ser40. Rolipram did elicit a significant induction of $\mathrm{TH}$ phosphorylation when coadministered with the antipsychotic agent, haloperidol. The lack of ef-

fect of rolipram alone on $\mathrm{TH}$ phosphorylation in vivo may be attributable to high dopamine $\mathrm{D}_{2}$ tone, which would be likely to exist in the intact animal but not in the isolated striatal slice preparation.

The PKA-dependent phosphorylation of TH at Ser40 increases the catalytic activity of TH (Harada et al., 1996; Dunkley
A.

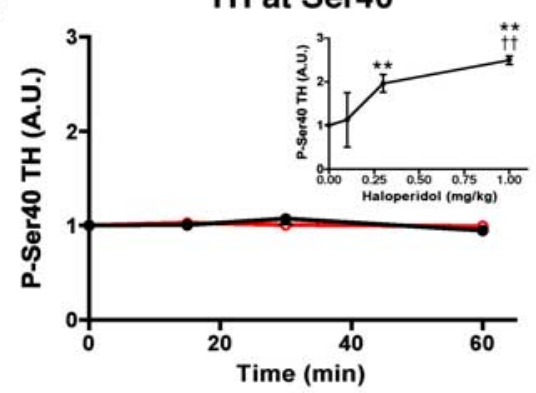

B.

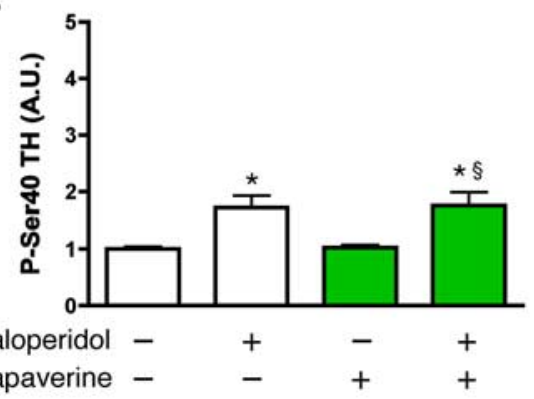

C.

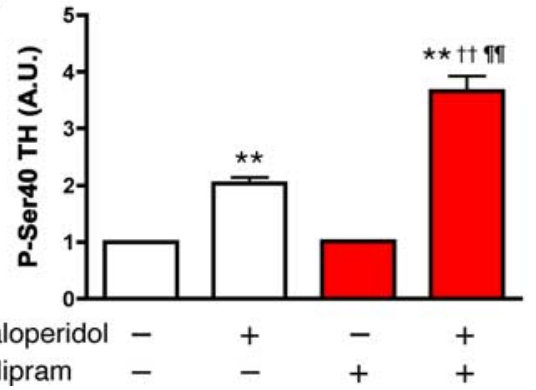

D.

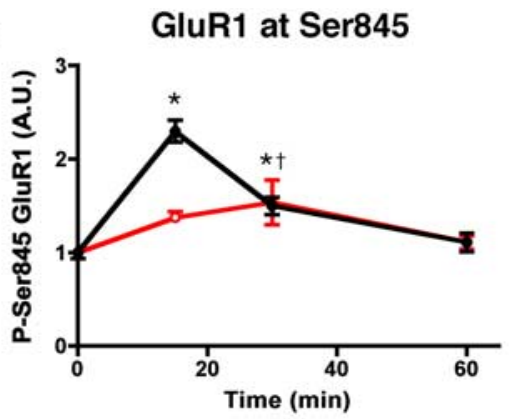

E.

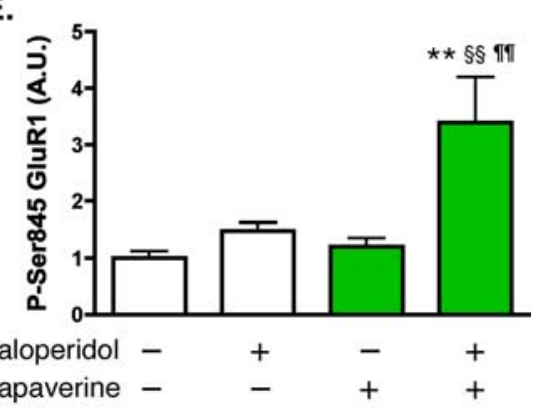

F.

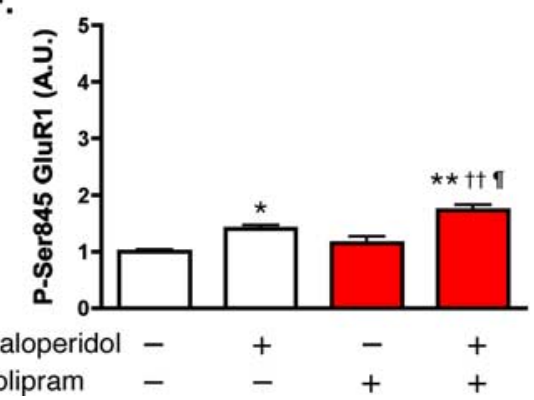

Figure 8. Effect of rolipram and papaverine on basal and haloperido-induced phosphorylation of TH and GluR1 in the striatum in vivo. Mice were injected with vehicle (saline) or PDE inhibitors alone or in combination with the neuroleptic compound haloperidol, and killed by focused microwave irradiation of the head at the indicated time points. Striatum was dissected and analyzed for the phosphorylation of TH at Ser40 and GluR1 at Ser845. $A$, Time course of the effect of papaverine and rolipram on TH Ser40 phosphorylation. Mice were treated systemically with vehicle ( 0 time point), rolipram ( $10 \mathrm{mg} / \mathrm{kg}$, i.p.; red open circles), or papaverine ( $30 \mathrm{mg} / \mathrm{kg}$, i.p.; black closed circles) and killed 15, 30, or $60 \mathrm{~min}$ later. Inset, Dose-response curve of haloperidol for phospho-Ser40 TH levels. Mice were treated with either vehicle (saline, 0 time point) or one of three doses of haloperidol $(0.1,0.3$, or $1.0 \mathrm{mg} / \mathrm{kg}$, i.p.) and killed 30 min later. ${ }^{* *} p<0.01$ compared with vehicle; ${ }^{\dagger \dagger} p<0.01$ compared with haloperidol at 0.3 $\mathrm{mg} / \mathrm{kg}$; one-way ANOVA followed by Newman-Keuls test. $\boldsymbol{B}$, Cotreatment of mice with papaverine does not potentiate haloperidol-induced increases in phospho-Ser40 TH levels. Mice were treated with papaverine alone $(30 \mathrm{mg} / \mathrm{kg})$, haloperidol alone $(0.3 \mathrm{mg} / \mathrm{kg})$, or both, and killed 30 min later. ${ }^{*} p<0.05$ compared with vehicle; ${ }^{\S} p<0.05$ compared with papaverine alone; one-way ANOVA followed by Newman-Keuls test. C, Cotreatment of mice with rolipram potentiates haloperidol-induced increases in phospho-Ser40 TH levels. Mice were treated with rolipram $(10 \mathrm{mg} / \mathrm{kg})$ alone, haloperidol alone $(0.3 \mathrm{mg} / \mathrm{kg})$, or both, and killed 30 min later. ${ }^{* *} p<0.01$ compared with vehicle; ${ }^{\text {t十 }} p<0.01$ compared with rolipram alone; ${ }^{\text {919 }} p<0.01$ compared with haloperidol alone; one-way ANOVA followed by Newman-Keuls test. $\boldsymbol{D}$, Time course of the effect of papaverine (black closed circles) and rolipram (red open circles) on GluR1 Ser845 phosphorylation. Striatal samples were prepared as described in $A .{ }^{*} p<$ 0.05 compared with time 0 for papaverine; ${ }^{\dagger} p<0.05$ compared with time 0 for rolipram; one-way ANOVA followed by NewmanKeuls test. $\boldsymbol{E}$, Cotreatment of mice with papaverine, as described in $\boldsymbol{B}$, potentiates haloperidol-induced increase in phosphoSer845 GluR1 level. ${ }^{* *} p<0.01$ compared with vehicle; ${ }^{\S \S} p<0.01$ compared with papaverine alone; ${ }^{\text {q19 }} p<0.01$ compared with haloperidol alone; one-way ANOVA followed by Newman-Keuls test. $\boldsymbol{F}$, Cotreatment of mice with rolipram, as described in $\boldsymbol{C}$, slightly but significantly potentiates haloperidol-induced increases in phospho-Ser845 GluR1 levels. ${ }^{*} p<0.05,{ }^{* *} p<0.01$ compared with vehicle; ${ }^{+\dagger} p<0.01$ compared with rolipram alone; $p<0.05$ compared with haloperidol alone; one-way ANOVA followed by Newman-Keuls test. Error bars indicate SEM.

et al., 2004), the rate-limiting step in dopamine biosynthesis ( $\mathrm{Na}$ gatsu et al., 1964). The inhibition of PDE4 and consequent enhancement of $\mathrm{TH}$ phosphorylation at Ser40 in the presence of haloperidol was accompanied by an increase in DOPAC/dopamine ratio in the striatum in vivo. This increase in relative DOPAC concentration reflects an increased metabolism of dopa- 
Table 1. Effect of rolipram and papaverine on basal and haloperidol-induced levels of dopamine and dopamine metabolites DOPAC and HVA

\begin{tabular}{|c|c|c|c|c|c|}
\hline & $\mathrm{DA}$ & DOPAC & HVA & DOPAC/DA & HVA/DA \\
\hline Control & $15.63 \pm 0.45$ & $0.77 \pm 0.05$ & $1.12 \pm 0.08$ & $5.32 \pm 0.21$ & $7.72 \pm 0.32$ \\
\hline Haloperidol & $12.80 \pm 0.89$ & $2.90 \pm 0.20^{* *}$ & $2.94 \pm 0.24^{* *}$ & $22.67 \pm 0.52^{* *}$ & $22.93 \pm 0.62^{* *}$ \\
\hline Rolipram & $18.22 \pm 1.33$ & $1.05 \pm 0.04$ & $1.25 \pm 0.10$ & $5.85 \pm 0.29$ & $6.86 \pm 0.24$ \\
\hline Papaverine & $15.31 \pm 1.38$ & $1.05 \pm 0.13$ & $1.38 \pm 0.12$ & $6.80 \pm 0.36$ & $9.01 \pm 0.18$ \\
\hline Haloperidol plus rolipram & $12.72 \pm 0.37$ & $4.06 \pm 0.16^{* * \text {, } \mathrm{t} \text {,११ }}$ & $2.81 \pm 0.14^{* *, t \dagger}$ & 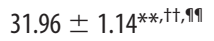 & $22.02 \pm 0.60^{* *,+t \dagger}$ \\
\hline Haloperidol plus papaverine & $11.69 \pm 1.20$ & $2.82 \pm 0.23^{* *, \S \S}$ & $2.27 \pm 0.24^{* *, \S \S, 9}$ & $24.52 \pm 1.04^{* *, \S \S}$ & 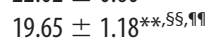 \\
\hline
\end{tabular}

Mice were treated with vehicle, rolipram $(10 \mathrm{mg} / \mathrm{kg}$ ) alone, papaverine $(30 \mathrm{mg} / \mathrm{kg}$ ) alone, or in combination with haloperidol $(0.3 \mathrm{mg} / \mathrm{kg})$ and killed 30 min later by focused microwave irradiation. Striatum was dissected and analyzed for dopamine (DA) and its metabolites, DOPAC and HVA. Data represent means \pm SEM for $4-5$ experiments. ${ }^{* *} p<0.01$ compared with control; ${ }^{\dagger \dagger} p<0.01$ compared with rolipram alone; ${ }^{\$ \S} p<0.01$ compared with papaverine alone; ${ }^{\sharp 1} p<$ $0.05,{ }^{\mathrm{q1}} p<0.01$ compared with haloperidol alone; one-way ANOVA followed by Newman-Keuls test.

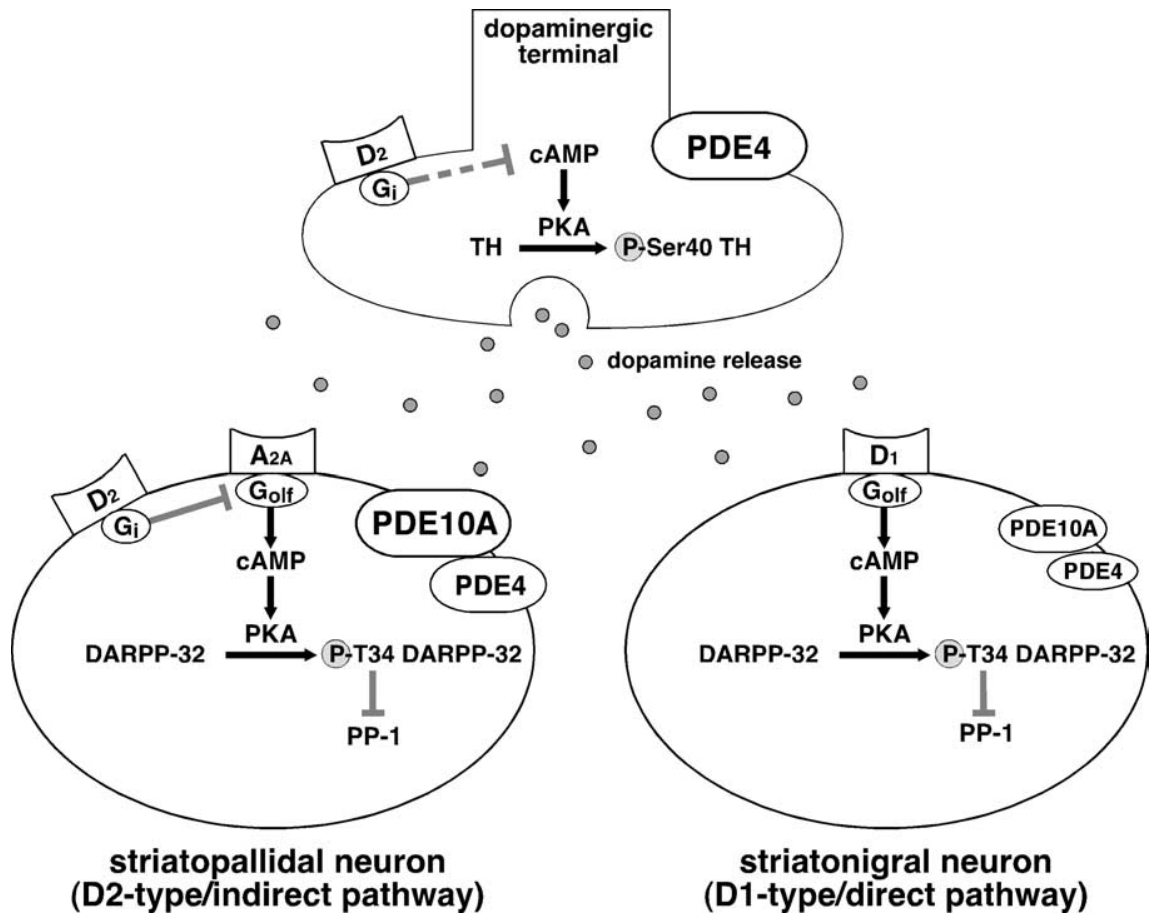

Figure 9. Differential role of PDE10A and PDE4 in striatal neurons and at dopaminergic terminals. This study provides evidence for differential expression and action of PDE10A and PDE4 in the striatum. PDE10A is expressed in two types of striatal neurons: $D_{1}$ receptor-enriched striatonigral and $D_{2}$ receptor-enriched striatopallidal neurons. The inhibition of PDE10A by papaverine potentiates the adenosine $A_{2 A}$ receptor-induced increase in DARPP- 32 phosphorylation, counteracts the dopamine $D_{2}$ receptor-induced decrease in DARPP-32 phosphorylation in striatopallidal neurons, and potentiates the dopamine $D_{1}$ receptor-induced increase in DARPP-32 phosphorylation in striatonigral neurons. PDE4 predominantly functions at dopaminergic terminals, and an inhibition of PDE4 by rolipram results in an increase in TH phosphorylation and dopamine synthesis. The inhibition of PDE4 also increases DARPP-32 Thr34 phosphorylation, preferentially in striatopallidal neurons, and potentiates the adenosine $A_{2 A}$ receptor-induced increase in DARPP-32 phosphorylation in these neurons.

mine by the action of monoamine oxidase (MAO) at dopaminergic terminals and reflects an increased dopamine biosynthesis rate in dopaminergic neurons. Released dopamine can also be converted to HVA at extraneuronal sites, through the sequential metabolism by COMT (catechol-O-methyltransferase) and MAO. Rolipram treatment did not affect the HVA/dopamine ratio, indicating that the primary effect of the inhibitor is an increase in the metabolism of newly synthesized dopamine by $\mathrm{MAO}$ at dopaminergic terminals, without an accompanying increase in dopamine release. Together, these data are consistent with results from previous studies in which rolipram was found to increase dopamine synthesis without altering dopamine release (Schoffelmeer et al., 1985; Yamashita et al., 1997a,b). The data extend those observations by demonstrating that phosphorylation of TH at Ser40 is a likely mechanism for mediating the action of rolipram on dopamine synthesis.

The PDE4 isoform responsible for effects at dopaminergic terminals has yet to be characterized. PDE4A and PDE4D mRNA have been detected by in situ hybridization in the substantia nigra (Pérez-Torres et al., 2000). However, a separate immunohistochemical study reported moderate expression of PDE4B and low expression of PDE4D in the same brain region (Cherry and Davis, 1999). Biochemical analysis of TH phosphorylation and dopamine turnover in the striatum from PDE4A, PDE4B, and PDE4D knock-out mice may be required to identity the PDE4 subtype responsible for the regulation of dopamine biosynthesis at dopaminergic terminals observed here.

\section{Role of PDE4 in striatal neurons}

PDE4 plays a major role in regulating dopamine synthesis at dopaminergic terminals, and also regulates cAMP/PKA signaling in striatal neurons. The expression of PDE4B at mRNA and protein levels has previously been reported in caudate-putamen (Cherry and Davis, 1999; PérezTorres et al., 2000). We used transgenic mice expressing Flag and Myc under the control of dopamine $\mathrm{D}_{1}$ and $\mathrm{D}_{2}$ receptor promoters, respectively, to compare the levels of PDE4B expression in the two major, functionally distinct subpopulations of medium spiny neurons by immunohistochemistry. The expression level of PDE4B was higher in striatopallidal neurons than that in striatonigral neurons. Consistent with this observation, we found that PDE4 inhibition selectively potentiated cAMP/PKA signaling in striatopallidal neurons. Rolipram treatment augmented phosphorylation of Thr34 DARPP-32 in response to an adenosine $\mathrm{A}_{2 \mathrm{~A}}$ receptor agonist, but had no effect on phosphorylation mediated by a dopamine $\mathrm{D}_{1}$ receptor agonist. These results suggest that PDE4 preferentially regulates cAMP/PKA signaling in striatopallidal neurons. Thus, cAMP/PKA signaling in striatopallidal neurons is regulated by at least two PDEs, PDE10A and PDE4, although the impact of PDE4 inhibition is less robust than that of PDE10A inhibition. The increase in CAMP/PKA signaling in striatopallidal neurons elicited by the PDE4 inhibitor, rolipram, would be expected to oppose dopamine $\mathrm{D}_{2}$ receptor signaling in these cells, similar to the effects of the PDE10A inhibitor, papaverine.

The PDE4 inhibitor, rolipram, like the PDE10A inhibitor, papaverine, inhibits dopamine $\mathrm{D}_{2}$ receptor signaling consistent 
with the pharmacological profile of an antipsychotic medication. Interestingly, at the same time, rolipram stimulates dopamine synthesis, indicating that PDE4 inhibition raises dopaminergic tone with mild inhibition of dopamine $\mathrm{D}_{2}$ receptor signaling in the striatum. This pharmacological profile is similar to that of some atypical antipsychotic medications, and may explain the antipsychotic activity of rolipram observed in animal models of schizophrenia, in which the compound rescued amphetamineinduced reductions in auditory-evoked potentials (Maxwell et al., 2004), MK801 [(+)-5-methyl-10,11-dihydro-5H-dibenzo[a,d]cyclohepten-5,10-imine maleate]-induced deficits in latent inhibition (Davis and Gould, 2005), and amphetamine-induced deficits in prepulse inhibition (Kanes et al., 2007). Among PDE4 subtypes, PDE4B is a possible target for rolipram, because the inhibition of conditioned avoidance responding by rolipram was attenuated in PDE4B knock-out mice (Siuciak et al., 2007, 2008). Because the nonselective PDE4 inhibitors including rolipram are known to induce the side effect of nausea and vomiting possibly via inhibition of PDE4D (Robichaud et al., 2002), the development of a PDE4B-selective inhibitor may be necessary for clinical trials in the treatment of psychiatric disorders.

In conclusion, the present study employs pharmacological, genetic, and neuroanatomical approaches to dissect the contribution of PDE4 and PDE10A to CAMP/PKA signaling in the striatum. Our studies reveal that PDE10A predominantly regulates cAMP/PKA signaling in medium spiny striatal neurons, as exemplified by the state of phosphorylation of DARPP-32, acting like a dopamine $\mathrm{D}_{2}$ antagonist in striatopallidal neurons. In contrast, PDE4 predominantly regulates $\mathrm{TH}$ phosphorylation at dopaminergic terminals. Thus, PDE4 and PDE10A have distinct roles in striatal dopaminergic neurotransmission conferred by their discrete cellular localization.

\section{References}

Bateup H, Svenningsson P, Kuroiwa M, Gong S, Nishi A, Heintz N, Greengard P (2008) Differential effects of psychostimulants and antipsychotics on DARPP-32 phosphorylation in striatonigral and striatopallidal neurons. Nat Neurosci 11:932-939.

Becker A, Grecksch G (2008) Phosphodiesterase inhibitors-are they potential neuroleptic drugs? Behav Brain Res 186:155-160.

Bender AT, Beavo JA (2006) Cyclic nucleotide phosphodiesterases: molecular regulation to clinical use. Pharmacol Rev 58:488-520.

Boyar WC, Altar CA (1987) Modulation of in vivo dopamine release by D2 but not D1 receptor agonists and antagonists. J Neurochem 48:824-831.

Cherry JA, Davis RL (1999) Cyclic AMP phosphodiesterases are localized in regions of the mouse brain associated with reinforcement, movement, and affect. J Comp Neurol 407:287-301.

Coskran TM, Morton D, Menniti FS, Adamowicz WO, Kleiman RJ, Ryan AM, Strick CA, Schmidt CJ, Stephenson DT (2006) Immunohistochemical localization of phosphodiesterase 10A in multiple mammalian species. J Histochem Cytochem 54:1205-1213.

Davis JA, Gould TJ (2005) Rolipram attenuates MK-801-induced deficits in latent inhibition. Behav Neurosci 119:595-602.

Dunkley PR, Bobrovskaya L, Graham ME, von Nagy-Felsobuki EI, Dickson PW (2004) Tyrosine hydroxylase phosphorylation: regulation and consequences. J Neurochem 91:1025-1043.

Fienberg AA, Hiroi N, Mermelstein PG, Song W, Snyder GL, Nishi A, Cheramy A, O'Callaghan JP, Miller DB, Cole DG, Corbett R, Haile CN, Cooper DC, Onn SP, Grace AA, Ouimet CC, White FJ, Hyman SE, Surmeier DJ, Girault J, Nestler EJ, Greengard P (1998) DARPP-32, regulator of the efficacy of dopaminergic neurotransmission. Science 281:838-842.

Fiumara F, Giovedì S, Menegon A, Milanese C, Merlo D, Montarolo PG, Valtorta F, Benfenati F, Ghirardi M (2004) Phosphorylation by cAMPdependent protein kinase is essential for synapsin-induced enhancement of neurotransmitter release in invertebrate neurons. J Cell Sci 117:5145-5154.

Fujishige K, Kotera J, Michibata H, Yuasa K, Takebayashi S, Okumura K,
Omori K (1999) Cloning and characterization of a novel human phosphodiesterase that hydrolyzes both cAMP and cGMP (PDE10A). J Biol Chem 274:18438-18445.

Fukuda T, Aika Y, Heizmann CW, Kosaka T (1996) Dense GABAergic input on somata of parvalbumin-immunoreactive GABAergic neurons in the hippocampus of the mouse. Neurosci Res 26:181-194.

Girault JA, Valjent E, Caboche J, Hervé D (2007) ERK2: a logical AND gate critical for drug-induced plasticity? Curr Opin Pharmacol 7:77-85.

Greengard P, Allen PB, Nairn AC (1999) Beyond the dopamine receptor: the DARPP-32/protein phosphatase-1 cascade. Neuron 23:435-447.

Harada K, Wu J, Haycock JW, Goldstein M (1996) Regulation of L-DOPA biosynthesis by site-specific phosphorylation of tyrosine hydroxylase in AtT-20 cells expressing wild-type and serine 40-substituted enzyme. J Neurochem 67:629-635.

Hebb AL, Robertson HA (2007) Role of phosphodiesterases in neurological and psychiatric disease. Curr Opin Pharmacol 7:86-92.

Hervé D, Le Moine C, Corvol JC, Belluscio L, Ledent C, Fienberg AA, Jaber M, Studler JM, Girault JA (2001) G $\alpha_{\text {olf }}$ levels are regulated by receptor usage and control dopamine and adenosine action in the striatum. J Neurosci 21:4390-4399.

Kanes SJ, Tokarczyk J, Siegel SJ, Bilker W, Abel T, Kelly MP (2007) Rolipram: a specific phosphodiesterase 4 inhibitor with potential antipsychotic activity. Neuroscience 144:239-246.

Kehr W, Debus G, Neumeister R (1985) Effects of rolipram, a novel antidepressant, on monoamine metabolism in rat brain. J Neural Transm 63:1-12.

Maxwell CR, Kanes SJ, Abel T, Siegel SJ (2004) Phosphodiesterase inhibitors: a novel mechanism for receptor-independent antipsychotic medications. Neuroscience 129:101-107.

Menniti FS, Faraci WS, Schmidt CJ (2006) Phosphodiesterases in the CNS: targets for drug development. Nat Rev Drug Discov 5:660-670.

Menniti FS, Chappie TA, Humphrey JM, Schmidt CJ (2007) Phosphodiesterase $10 \mathrm{~A}$ inhibitors: a novel approach to the treatment of the symptoms of schizophrenia. Curr Opin Investig Drugs 8:54-59.

Nagatsu T, Levitt M, Udenfriend S (1964) Tyrosine hydroxylase. The initial step in norepinephrine biosynthesis. J Biol Chem 239:2910-2917.

Nishi A, Snyder GL, Greengard P (1997) Bidirectional regulation of DARPP-32 phosphorylation by dopamine. J Neurosci 17:8147-8155.

Nishi A, Watanabe Y, Higashi H, Tanaka M, Nairn AC, Greengard P (2005) Glutamate regulation of DARPP-32 phosphorylation in neostriatal neurons involves activation of multiple signaling cascades. Proc Natl Acad Sci U S A 102:1199-1204.

O'Callaghan JP, Sriram K (2004) Focused microwave irradiation of the brain preserves in vivo protein phosphorylation: comparison with other methods of sacrifice and analysis of multiple phosphoproteins. J Neurosci Methods 135:159-168.

Ouimet CC, LaMantia AS, Goldman-Rakic P, Rakic P, Greengard P (1992) Immunocytochemical localization of DARPP-32, a dopamine and cyclicAMP-regulated phosphoprotein, in the primate brain. J Comp Neurol 323:209-218.

Pérez-Torres S, Miró X, Palacios JM, Cortés R, Puigdoménech P, Mengod G (2000) Phosphodiesterase type 4 isozymes expression in human brain examined by in situ hybridization histochemistry and $[3 \mathrm{H}]$ rolipram binding autoradiography. Comparison with monkey and rat brain. J Chem Neuroanat 20:349-374.

Polli JW, Kincaid RL (1994) Expression of a calmodulin-dependent phosphodiesterase isoform (PDE1B1) correlates with brain regions having extensive dopaminergic innervation J Neurosci 14:1251-1261.

Reed TM, Repaske DR, Snyder GL, Greengard P, Vorhees CV (2002) Phosphodiesterase 1B knock-out mice exhibit exaggerated locomotor hyperactivity and DARPP-32 phosphorylation in response to dopamine agonists and display impaired spatial learning. J Neurosci 22:5188-5197.

Robichaud A, Stamatiou PB, Jin SL, Lachance N, MacDonald D, Lalibert F, Liu S, Huang Z, Conti M, Chan CC (2002) Deletion of phosphodiesterase $4 \mathrm{D}$ in mice shortens alpha(2)-adrenoceptor-mediated anesthesia, a behavioral correlate of emesis. J Clin Invest 110:1045-1052.

Schoffelmeer AN, Wardeh G, Mulder AH (1985) Cyclic AMP facilitates the electrically evoked release of radiolabelled noradrenaline, dopamine and 5-hydroxytryptamine from rat brain slices. Naunyn Schmiedebergs Arch Pharmacol 330:74-76.

Seino S, Shibasaki T (2005) PKA-dependent and PKA-independent pathways for cAMP-regulated exocytosis. Physiol Rev 85:1303-1342. 
Siuciak JA, McCarthy SA, Chapin DS, Fujiwara RA, James LC, Williams RD, Stock JL, McNeish JD, Strick CA, Menniti FS, Schmidt CJ (2006a) Genetic deletion of the striatum-enriched phosphodiesterase PDE10A: evidence for altered striatal function. Neuropharmacology 51:374-385.

Siuciak JA, Chapin DS, Harms JF, Lebel LA, McCarthy SA, Chambers L, Shrikhande A, Wong S, Menniti FS, Schmidt CJ (2006b) Inhibition of the striatum-enriched phosphodiesterase PDE10A: a novel approach to the treatment of psychosis. Neuropharmacology 51:386-396.

Siuciak JA, Chapin DS, McCarthy SA, Martin AN (2007) Antipsychotic profile of rolipram: efficacy in rats and reduced sensitivity in mice deficient in the phosphodiesterase-4B (PDE4B) enzyme. Psychopharmacology (Berl) 192:415-424.

Siuciak JA, McCarthy SA, Chapin DS, Martin AN (2008) Behavioral and neurochemical characterization of mice deficient in the phosphodiesterase-4B (PDE4B) enzyme. Psychopharmacology (Berl) 197:115-126.

Stoof JC, Kebabian JW (1981) Opposing roles for D-1 and D-2 dopamine receptors in efflux of cyclic AMP from rat neostriatum. Nature 294:366-368.

Svenningsson P, Nishi A, Fisone G, Girault JA, Nairn AC, Greengard P (2004) DARPP-32: an integrator of neurotransmission. Annu Rev Pharmacol Toxicol 44:269-296.
Wadenberg ML, Hicks PB (1999) The conditioned avoidance response test re-evaluated: is it a sensitive test for the detection of potentially atypical antipsychotics? Neurosci Biobehav Rev 23:851-862.

Xie Z, Adamowicz WO, Eldred WD, Jakowski AB, Kleiman RJ, Morton DG, Stephenson DT, Strick CA, Williams RD, Menniti FS (2006) Cellular and subcellular localization of PDE10A, a striatum-enriched phosphodiesterase. Neuroscience 139:597-607.

Yabuuchi K, Kuroiwa M, Shuto T, Sotogaku N, Snyder GL, Higashi H, Tanaka M, Greengard P, Nishi A (2006) Role of adenosine A1 receptors in the modulation of dopamine D1 and adenosine A2A receptor signaling in the neostriatum. Neuroscience 141:19-25.

Yamashita N, Miyashiro M, Baba J, Sawa A (1997a) Rolipram, a selective inhibitor of phosphodiesterase type 4, pronouncedly enhanced the forskolin-induced promotion of dopamine biosynthesis in primary cultured rat mesencephalic neurons. Jpn J Pharmacol 75:91-95.

Yamashita N, Hayashi A, Baba J, Sawa A (1997b) Rolipram, a phosphodiesterase-4-selective inhibitor, promotes the survival of cultured rat dopaminergic neurons. Jpn J Pharmacol 75:155-159.

Zhu G, Okada M, Yoshida S, Hirose S, Kaneko S (2004) Pharmacological discrimination of protein kinase associated exocytosis mechanisms between dopamine and 3,4-dihydroxyphenylalanine in rat striatum using in vivo microdialysis. Neurosci Lett 363:120-124. 